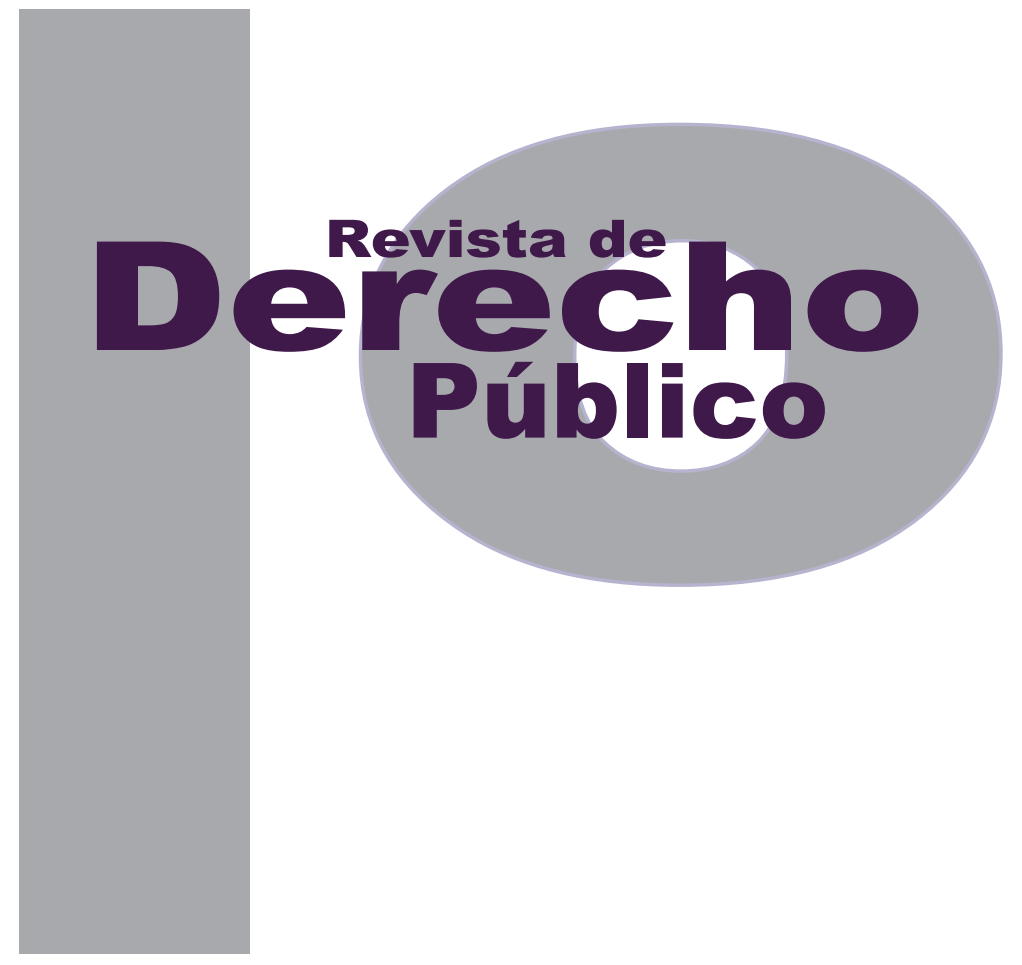

\title{
¿EDUCACIÓN INCLUSIVA? ANÁLISIS DEL MARCO JURÍDICO SOBRE EL DERECHO DE ACCESO Y PERMANENCIA EN LA EDUCACIÓN SUPERIOR PARA LAS PERSONAS SORDAS EN LA CIUDAD DE BOGOTÁ
}

\author{
ANDREA LUNA RUIZ
}

Artículo de revisión

DOI: http://dx.doi.org/10.15425/redepub.33.2014.18

Universidad de los Andes

Facultad de Derecho

Revista de Derecho Público N. ${ }^{\circ} 33$

Julio - Diciembre de 2014. ISSN 1909-7778 


\title{
¿Educación inclusiva? Análisis del marco jurídico sobre el derecho de acceso y permanencia en la educación superior para las personas Sordas en la ciudad de Bogotá
}

\section{Resumen}

El trabajo de investigación que aquí se presenta pretende esclarecer la situación actual de las personas Sordas* en la ciudad de Bogotá, en lo que se refiere a la permanencia y al acceso a la educación superior. Está basado en el análisis del marco jurídico nacional e internacional respecto a las personas con discapacidad y específicamente a la comunidad Sorda, e intenta determinar si el marco jurídico existente es o no suficiente para garantizarles a cabalidad el derecho a la educación, teniendo en cuenta las variables de permanencia y acceso al sistema educativo y el debate sobre si dicha comunidad puede ser o no considerada una minoría lingüística. Asimismo, se intentan determinar las fallas de la jurisprudencia, la legislación y las políticas públicas que hasta el momento han sido implementadas, y las posibles soluciones que se podrían adoptar, desde la óptica constitucional de los derechos fundamentales a la igualdad y la educación de las personas con discapacidad, todo esto bajo el modelo social que define dicho concepto.

Palabras clave: personas Sordas, comunidad Sorda, personas en condición de discapacidad, educación inclusiva, inclusión social, educación superior, derecho a la educación, derecho a la igualdad, ajustes razonables, política institucional.

\section{Inclusive education? Analysis of the legal framework on the right of access and permanence to higher education for Deaf people in Bogota}

\begin{abstract}
This research aims to clarify the current situation of the Deaf community in Bogotá in regard to the permanence and access to higher education. The study was carried out based on the analysis of the current national and international legal framework that relates to people with disabilities, and specifically to the Deaf community. With a deep analysis of the existing legal framework, this paper will attempt to determine whether or not this framework is sufficient in fully guaranteeing the right to education of Deaf people, taking into account the variables of permanence and access to education, and the discussion on whether the Deaf community may or may not be considered a linguistic minority. Furthermore, this investigation will attempt to determine the flaws in case law, legislation and public policies that have thus far been implemented, while also highlighting policy recommendations that can be adopted from a constitutional standpoint on the fundamental rights to equality and education for people with disabilities, all under the social model that defines this concept.
\end{abstract}

Keywords: deaf people, deaf community, people with disabilities, inclusive education, social inclusion, higher education, right to education, right to equality, institutional policy.

\section{Educação inclusiva? Análise do marco jurídico sobre o direito de acesso e permanência na educação superior para as pessoas Surdas na cidade de Bogotá}

\section{Resumo}

O trabalho de pesquisa que aqui é apresentado pretende esclarecer a situação atual das pessoas Surdas na cidade de Bogotá, no que se refere à permanência e o acesso à educação superior. Está baseado na análise do marco jurídico nacional e internacional referido às pessoas com deficiência e especificamente à comunidade Surda, e tenta determinar se o marco jurídico existente é ou não é suficiente para garantir-lhes o direito à educação, levando em consideração as variáveis de permanência e acesso ao sistema educativo e o debate sobre se dita comunidade pode ser ou não considerada uma minoria linguística. Assim mesmo, tenta-se determinar as falhas da jurisprudência, a legislação e as políticas públicas que até o momento têm sido implementadas, e as possíveis soluções que poderiam ser adotadas, sob a ótica constitucional dos direitos fundamentais à igualdade e a educação das pessoas com deficiência, tudo isto sob o modelo social que define dito conceito.

Palavras-chave: pessoas Surdas, comunidade Surda, pessoas em condição de deficiência, educação inclusiva, inclusão social, educação superior, direito à educação, direito à igualdade, ajustes razoáveis, política institucional.

* En el libro Estudios sobre los derechos de las personas sordas, Agustina Palacios (2010) afirma que desde una mirada más compleja, se puede hacer una diferenciación entre una persona Sorda (con mayúscula) y una persona sorda (con minúscula). La palabra en minúscula se refiere a una característica física (no oír), mientras que el término Sordo con mayúsculas, se refiere a los aspectos culturales y lingüísticos que van ligados con el hecho de ser Sordo. En este trabajo de investigación se tendrá en cuenta esta diferenciación. 


\title{
¿Educación inclusiva? Análisis del marco jurídico sobre el derecho de acceso y permanencia en la educación superior para las personas Sordas en la ciudad de Bogotá*
}

\author{
Andrea Luna Ruiz**
}

\begin{abstract}
SUMARIO
Introducción - I. ESTADO DEL ARTE - A. El concepto de discapacidad - 1. Los modelos de discapacidad - 1.1. Modelo de prescindencia - 1.2. Modelo rehabilitador - 1.3. Modelo social de discapacidad - B. La identidad cultural de la población Sorda - 1. Escuelas para la educación de las personas Sordas - 1.1. Escuela oralista - 1.2. Escuela gestual o bilingüe - C. Lengua de Señas Colombiana - D. La educación superior - E. Educación superior inclusiva - II. MARCO JURÍDICO REGULATORIO - A. Instrumentos jurídicos internacionales - 1. Convención sobre los Derechos de las Personas con Discapacidad de las Naciones Unidas - 2. Otros instrumentos internacionales de derechos humanos - $B$. Instrumentos jurídicos nacionales - 1. Constitución Política de Colombia - 1.1. Sobre el derecho a la igualdad - 1.2. Sobre el derecho a la educación - 2. Legislación, decretos y resoluciones - 3. Jurisprudencia de la Corte Constitucional de Colombia - III. APUNTES FINALES - Referencias - Anexos.
\end{abstract}

* $\quad$ Cómo citar este artículo: Luna Ruiz, A. (Diciembre, 2014). ¿Educación inclusiva? Análisis del marco jurídico sobre el derecho de acceso y permanencia en la educación superior para las personas Sordas en la ciudad de Bogotá. Revista de Derecho Público, 33. Universidad de los Andes (Colombia).

** Abogada de la Universidad de los Andes con opción en Psicología Social de la misma universidad. Gran interés en temas relacionados con los derechos humanos, especialmente en los derechos de las personas con discapacidad, derechos de los niños y niñas y equidad de género. En el último año trabajó en PAllS —Programa de Acción por la Igualdad y la Inclusión Social—, clínica jurídica que tiene por fin promover, defender y promocionar los derechos de las personas de especial protección constitucional. Cursa V Nivel de Lengua de Señas Colombiana en la Federación Nacional de Sordos de Colombia (Fenascol). En este año, trabajó como voluntaria en China con niños con discapacidad de escasos recursos. Actualmente, es analista jurídica del PTP -Programa de Transformación Productiva- del Ministerio de Comercio, Industria y Turismo. Correo: a.luna70@uniandes.edu.co, alunaruiz27@gmail.com 
Introducción

El mundo se construye

de maneras diferentes.

El presente trabajo busca documentar y analizar críticamente la situación de las personas Sordas en Bogotá, en relación con su acceso a la educación superior y permanencia en esta, a la luz del marco jurídico internacional y nacional sobre discapacidad, discriminación y derecho a la educación, con miras a aportar a la construcción de políticas públicas efectivas para la ciudad de Bogotá.

Para ello, en primer lugar se presenta y compara la información estadística oficial sobre el acceso a la educación superior de las personas Sordas en la ciudad de Bogotá. En segundo lugar, se analiza el marco jurídico nacional e internacional sobre discapacidad y discriminación por motivos de discapacidad, con especial énfasis en la comunidad Sorda, así como sobre el derecho a la educación. En tercer lugar, se presentan las experiencias de algunos estudiantes Sordos que están cursando programas de educación superior y de otros que no pudieron acceder a ella. En cuarto lugar, se describen las diferentes perspectivas que existen sobre la educación inclusiva, y se exponen las medidas o políticas públicas que, a mi juicio, se deben adoptar en la ciudad para garantizarles a las personas Sordas la permanencia y el acceso a la educación superior. Los resultados de la presente investigación serán traducidos a Lengua de Señas Colombiana (LSC), presentados en un video a las personas Sordas que participaron en el estudio y puestos a disposición de la comunidad en general.

En 2002, el Departamento Administrativo Nacional de Estadística (DANE) y el Ministerio de Educación Nacional (MEN) acordaron implementar una estrategia de recolección de datos continua sobre las personas con discapacidad, en la que se adoptó el enfoque de discapacidad recomendado por la Organización Mundial de la Salud (oms) ${ }^{1}$ (DANE, 2008). Según los datos obtenidos por el DANE en el censo de 2005, el número de personas con algún tipo de discapacidad en nuestro país fue de 2'647.000 -población de referencia: 42'092.000 habitantes- (Fenascol, 2011). ${ }^{2}$

Asimismo, en el censo se estimó que la población con discapacidad auditiva ${ }^{3}$ en Colombia es de 446.179 personas, es decir, un 17,26\% del total de las personas con discapacidad. Según los datos de Fenascol (2011), el total de personas con discapacidad auditiva es 456.642, una cifra que comparte el porcentaje del 17,3\% estipulado por el DANE.

1 La oms acoge como marco conceptual de la discapacidad la Clasificación Internacional de Funcionamiento, la Discapacidad y la Salud (CIF). El concepto de discapacidad se analizará con posterioridad. La forma de conceptualizar la discapacidad es de gran importancia debido a que se pueden variar los enfoques y los puntos de partida, haciendo que los datos que muestran la problemática se vean afectados por una idea errada.

2 Ver las tablas 1 a 4 en el documento anexo, para obtener información estadística sobre las personas con discapacidad.

3 Vale la pena aclarar que la discapacidad auditiva incluye a las personas sordas y a las personas que presenten cualquier tipo de dificultad con el sentido de la audición. El presente trabajo se enfoca exclusivamente en el acceso a la educación de las personas sordas. 
El DANE (2008) hizo un gran esfuerzo por medir la variable de educación bajo la óptica de los derechos de las personas con discapacidad: ${ }^{4}$ se determinó que el total de personas con discapacidad auditiva en Bogotá es de 5.744, de las cuales: i) 42 tienen un nivel educativo técnico incompleto; ii) 87 tienen un nivel educativo técnico completo; iii) 66 son universitarios sin títuIo; iv) 30 han obtenido un título universitario; y v) 1.221 no han podido acceder a ningún nivel de estudios. Las cifras hablan por sí solas, pues de 5.744 personas con discapacidad auditiva en Bogotá solo 30 han podido acceder a la educación superior $(0,52 \%){ }^{5}$

Las cifras han confirmado que la inclusión social en el sistema educativo no ha sido del todo efectiva, y este trabajo pretende mostrar que existen diferentes barreras y obstáculos que imposibilitan el acceso y la permanencia en la educación superior de las personas sordas. Al efecto, se aborda la siguiente pregunta central: ¿Son las políticas públicas de acceso y permanencia a la educación superior de las personas Sordas acordes con el marco jurídico nacional e internacional que se refiere a las personas con discapacidad, y suficientes para garantizar el derecho fundamental a la educación? La relevancia de la pregunta de investigación se resu-

$4 \quad$ El cuadro 34 (producto del censo de 2005), estipuló que: i) el total de personas con discapacidad en todas las localidades de Bogotá es de 378.354; ii) las personas con discapacidad que han accedido a la educación superior en Bogotá son 9.744; y iii) las personas con discapacidad que no han podido acceder a ningún nivel educativo son 76.824 .

Las cifras presentadas por el DANE y por Fenascol no están discriminadas entre personas sordas y con discapacidad auditiva, lo que hace difícil analizar la problemática de la comunidad sorda específicamente. me en la posibilidad de identificar y determinar los avances y fallas en la creación e implementación de las políticas públicas y, a su vez, en la posibilidad de dar soluciones más acertadas a la problemática.

Como premisa está la importancia de obtener unas conclusiones y construir unas propuestas incluyendo siempre la perspectiva de las personas Sordas sobre el tema de análisis. Moreno (1996), por ejemplo, centra su estudio en la importancia del empoderamiento de la población con discapacidad para la inclusión en el sistema educativo. La alianza entre el Estado, la academia y la sociedad civil -con y sin discapacidad-produce resultados importantes: cambios profundos y estructurados. González (2011) asegura que la tendencia histórica ha mostrado que se suelen generalizar y estandarizar comportamientos sobre las minorías, lo que muchas veces no representa las necesidades de dichas poblaciones.

Este documento es el resultado de un trabajo de campo de aproximadamente un año, que incluyó: i) Comparación, delimitación y análisis de información estadística y fuentes oficiales existentes sobre la población Sorda de Bogotá; ii) Participación e integración personal en la comunidad Sorda desde diciembre de 2012, en calidad de estudiante de Lsc en Fenascol; iii) Entrevistas a diferentes especialistas en temas de inclusión educativa -Jaime Collazos ${ }^{6}$, Carlos Pa-

6 Psicólogo con maestría en educación y doctorado en salud pública. Ha trabajado con personas con discapacidad, específicamente con personas sordas. Actualmente trabaja en el Ministerio de Salud en la respuesta del gobierno frente a las personas con discapacidad. 
rra $^{7}$, Diana Patricia Martínez ${ }^{8}$, Ricardo Becerra ${ }^{9}$ y Luis Giovanny $\mathrm{Gil}^{10}$ - y a personas en situación de discapacidad; iv) Documentación de las experiencias de varias personas Sordas en cuanto al acceso y permanencia en la educación superior, entre ellas varios profesores de Fenascol, cuatro jóvenes que expusieron sus vivencias individuales y otras participantes en grupos espontáneos en los que se pudieron discutir los obstáculos para el acceso y permanencia que han tenido que sortear.

Adicionalmente, las conclusiones de este documento serán presentadas en Lengua de Señas Colombiana a diferentes grupos de personas Sordas, con el fin de ofrecer el conocimiento construido de vuelta a la comunidad que es la principal fuente de este.

\section{ESTADO DEL ARTE}

\section{A. El concepto de discapacidad}

La discapacidad es un concepto que ha sido ampliamente definido por organismos interna-

7 Doctor en derechos fundamentales. Especialista en derecho constitucional. Abogado de la Universidad del Rosario. Trabajó en la construcción de la Ley 1618 de 2013.

8 Subgerente de Educación Inclusiva en la Fundación Saldarriaga Concha.

9 Diseñador industrial y persona usuaria de silla de ruedas. Ofrece consultorías de diseño inclusivo a instituciones y empresas públicas y privadas.

10 Trabaja en la subdirección de apoyo del Ministerio de Educación Nacional. Lidera el proceso de acompañamiento y seguimiento a la inclusión de la población con discapacidad y talentos excepcionales a la educación superior. Trabajó en el INSOR y es intérprete para personas sordas hace 25 años. cionales. ${ }^{11} \mathrm{~A}$ pesar de este intento de varias instituciones y organizaciones internacionales por definir el concepto de discapacidad y acercarlo cada vez más a la idea de dignidad humana y de igualdad, es evidente que dichas definiciones reflejan una visión deficitaria de la discapacidad al usar términos como "deficiencias", "problemas", "limitaciones" y "restricciones". Así, estos intentos de conceptualización no logran definir la discapacidad a partir de un modelo social que la considere como un problema que radica en el entorno y no que tiene su origen en las personas. Se continúan dando connotaciones negativas al concepto de discapacidad. ${ }^{12}$

Sin embargo, la Convención sobre los Derechos de las Personas con Discapacidad, de las $\mathrm{Na}$ ciones Unidas (CDPD) ha hecho el intento más acertado -aunque todavía tiene problemas en el lenguaje- al rehusarse a definir el término de manera unívoca y entender en su preámbulo,

11 Se puede revisar, por ejemplo, la definición de la Organización Mundial de Salud (2001) en la Clasificación internacional del funcionamiento de la discapacidad y de la salud (CIF), que habla de la discapacidad como "un término genérico que engloba deficiencias, limitaciones de actividad y restricciones para la participación. La discapacidad denota los aspectos negativos de la interacción entre personas con un problema de salud (como parálisis cerebral, síndrome de Down o depresión) y factores personales y ambientales (como actitudes negativas, transporte y edificios públicos inaccesibles, y falta de apoyo social)". Por su parte, el Banco Mundial y la oms (2011) en el Informe mundial sobre la discapacidad, afirman que "La discapacidad forma parte de la condición humana: casi todas las personas sufrirán algún tipo de discapacidad transitoria o permanente en algún momento de su vida, y las que lleguen a la senilidad experimentarán dificultades crecientes de funcionamiento. La discapacidad es compleja, y las intervenciones para superar las desventajas asociadas a ella son múltiples, sistémicas y varían según el contexto".

12 En el Seminario Permanente de Discusión Crítica, realizado en la Universidad Externado de Colombia el pasado 9 de abril, Agustina Palacios (2014) dejó claro que no está de acuerdo con el uso de palabras como "deficiencias" o "limitaciones", por traer connotaciones negativas a la condición de la persona, prefiere usar el término "diversidad funcional" por considerar que el lenguaje también crea realidad. 
que es "un concepto que evoluciona y que resulta de la interacción entre las personas con deficiencias y las barreras debidas a la actitud y al entorno que evitan su participación plena y efectiva en la sociedad, en igualdad de condiciones con las demás".

\section{Los modelos de discapacidad}

A lo largo de la historia y en todas las sociedades la discapacidad ha sido conceptualizada de distintas maneras, las cuales a su vez han determinado la forma en que las prácticas culturales y políticas públicas se materializan. El análisis de tales modelos es esencial para entender la postura adoptada en nuestro país actualmente, sobre todo en las políticas públicas en torno a la educación de las personas Sordas.

\subsection{Modelo de prescindencia}

El modelo de prescindencia considera que las causas que dan origen a la discapacidad tienen un motivo religioso, y que las personas con discapacidad son innecesarias para el desarrollo de cualquier comunidad, es decir, prescinde de esta población segregándola y catalogándola como "anormal" y como objeto de caridad. En este modelo "las personas con discapacidad se consideran innecesarias por diferentes razones: porque se estima que no contribuyen a las necesidades de la comunidad, que albergan mensajes diabólicos, que son la consecuencia del enojo de los dioses, o que - por lo desgraciadas-, sus vidas no merecen la pena ser vividas" (Palacios, 2008).
Dentro de este modelo se pueden identificar dos submodelos: el eugenésico y el de marginación. El primero ofrece como solución la implementación de medidas relativas a las leyes biológicas de la herencia, una de cuyas consecuencias según Palacios (2008), ha sido el infanticidio al momento de detectar un niño con diversidades funcionales congénitas. En el segundo submodelo la forma de alcanzar el objetivo es la exclusión de las personas con discapacidad a través de subestimación, compasión, temor, menosprecio o rechazo: "la exclusión parece ser la mejor solución y la respuesta social que genera mayor tranquilidad" (Palacios, 2008); los niños mueren como consecuencia de omisiones por parte de sus padres y los que logran alcanzar una edad adulta son objeto de caridad y mendicidad.

\subsection{Modelo rehabilitador}

El segundo modelo que apareció en la historia se denomina rehabilitador o médico, y se diferencia principalmente del modelo de prescindencia en que las causas de origen no son divinas ni religiosas, sino científicas: "se alude a la diversidad funcional en términos de salud o enfermedad" (Palacios, 2008). Este modelo afirma que las personas con discapacidad no son útiles en la medida en que no sean rehabilitadas -física, psíquica, mental y sensorialmente-, es decir, que las personas con discapacidad deben lograr asemejarse a las personas sin discapacidad en la mayor medida posible. Así, bajo este modelo la discapacidad equivale a un "déficit" o una "limitación", subestimando e ignorando las habilidades de las personas que supuestamen- 
te la padecen. Estas características hacen que se adopten actitudes paternalistas que se enfocan únicamente en el supuesto "déficit" que las personas con discapacidad presentan y en la necesidad de que sean "normalizadas".

\subsection{Modelo social de discapacidad}

Como su nombre lo indica, este modelo entiende que el origen de la discapacidad está en la sociedad; por consiguiente, no diferencia entre personas con o sin discapacidad y entiende que la opresión social que vive la población con discapacidad es el resultado de una sociedad que no ha logrado ofrecerles una inclusión real (Palacios, 2008). El modelo propone que la discapacidad sea vista desde las barreras, exclusiones, discriminaciones y actitudes negativas que la sociedad impone a las personas con discapacidad - de forma voluntaria e involuntaria-.

Una de las premisas fundamentales de este modelo es la igualdad, pues de ella se desprende la idea de equilibrio en las oportunidades y la posibilidad de tomar decisiones autónomamente, factores dejados a un lado por los modelos anteriormente mencionados. La discapacidad debe ser vista, entonces, desde la sociedad, con lo cual el verdadero problema surge a partir de las limitaciones que esta impone al no poder asegurar que las necesidades de las personas con discapacidad sean tenidas en cuenta dentro de su organización social (Palacios, 2008).

En el libro Estudio sobre los derechos de las personas sordas (Cuenca, Palacios, Ramiro, De Asís y Barranco, 2012), Rafael de Asís resume de manera genérica el modelo social de disca- pacidad en cuatro puntos que pueden servir para ilustrar el concepto:

a) El enfoque correcto para abordar la discapacidad desde un punto de vista normativo es el de los derechos humanos.

b) La discapacidad tiene un origen social por lo que las medidas tendientes a satisfacer los derechos de las personas con discapacidad deben tener como principal destinataria a la sociedad en general.

c) La discapacidad es, principalmente, una situación en la que se encuentran o pueden encontrarse las personas y no un rasgo individual que las caracterice.

d) Por todo lo anterior, la política normativa en el ámbito de los derechos humanos de las personas con discapacidad debe moverse en el plano de la igualdad y la no discriminación y, dentro de este, en el ámbito de la generalización de los derechos.

La historia de la discapacidad en Colombia hasta los años 90 tuvo un enfoque completamente clínico y estuvo asociada siempre con el sector salud. Sin embargo, el concepto de discapacidad comenzó a cambiar y a evolucionar. Este cambio, según Collazos (2014) -se puede ver más en el sector salud que en el sector de educación, que ha mantenido el mismo discurso desde hace varios años-, ha sido muy importante y se ha evidenciado en las políticas públicas de salud y de educación. Aun así, los rezagos del modelo médico y de prescindencia son 
evidentes en nuestro país, como se verá en las conclusiones que se presentarán a lo largo del presente trabajo.

\section{B. La identidad cultural de la población Sorda}

Actualmente, uno de los problemas más grandes a los que se enfrenta la comunidad Sorda es la categoría en que se encuentran en relación con la sociedad. Según Hurtado (2004), "siempre se ha sabido que los sordos constituyen una minoría, pero hasta hace muy poco se ha considerado que pueden existir como grupo social con una identidad y una lengua propia".

Son muchos los debates y posiciones de investigadores, docentes, comunidad oyente y no oyente, en cuanto a la posible legitimación de la comunidad Sorda como minoría. Según Fenascol (2011), una persona Sorda es aquella que no puede escuchar, por haber nacido sorda o por haber perdido su audición a lo largo de su vida. Dicha Federación es reiterativa cuando señala que las personas Sordas no deben ser consideradas personas enfermas:

LAS PERSONAS SORDA(S) NO SON ENFERMAS, no necesitan ninguna droga o tratamiento para curarse. LAS PERSONAS SORDAS USAN UN IDIOMA DIFERENTE, CON el que pueden aprender, compartir, actuar y expresarse libremente. El daño en la audición no afecta el desarrollo intelectual de los sordos. Para la mayoría de los sordos no es fácil aprender a hablar, para la mayoría de los oyentes es fácil aprender Lengua de Señas solo falta voluntad y esfuerzo para lograrlo (Fenascol, 2011, p. 1).
Ahora bien, las personas Sordas están unidas por diferentes vínculos sociales y culturales, y por una historia común que las constituye como una comunidad autónoma con pautas, objetivos y valores particulares. Como lo afirma Behares (1997), que la diferencia entre las comunidades de Sordos y de oyentes radique en el lenguaje, y no en la mera condición biológica de la pérdida de audición, las asemeja a comunidades étnicas, pues comparten un origen, una historia y un patrimonio cultural común construido por ellas mismas.

Glickman (1993) propone una clasificación de cuatro "identidades sordas":

i. La identidad oyente: la persona Sorda no se identifica a sí misma como Sorda, solo comparte la condición física con la comunidad Sorda, no por esto su cultura ni sus valores. A partir de una visión médica de la sordera, se niega todo su carácter cultural y el individuo hace todo lo posible por normalizarse mediante procesos de rehabilitación intensivos orientados a lograr que la persona se comunique oralmente o a que maneje un implante coclear. ${ }^{13}$

ii. La identidad marginal: la identidad del individuo es ambivalente, es decir, la persona no tiene todavía solidificada su identidad en ninguno de los grupos. Según Glickman, esta etapa es temporal, pues tarde o temprano el

13 Producto de alta tecnología que se implanta quirúrgicamente en personas con hipoacusia moderada y media. Este sistema transductor proporciona sonido imitando la audición natural al estimular el nervio auditivo de las personas con discapacidad auditiva (Cochlear, (2012). 
individuo debe ubicarse en un marco cultural de referencia.

iii. La identidad inmersa: se refiere a cuando el individuo se apropia de la identidad Sorda, hasta el punto de no buscar relación alguna con la comunidad oyente. Se idealiza la identidad Sorda.

iv. La identidad bicultural: el individuo se reconoce primero como persona, y luego como integrante de dos comunidades: Sorda y oyente.

\section{Escuelas para la educación de las personas Sordas}

Existen dos escuelas teóricas que discuten principalmente la manera más adecuada para educar a las personas Sordas: la oralista y la gestual. ${ }^{14}$

\subsection{Escuela oralista}

“La vista por el oído”15

Esta escuela considera que la oralización es la forma adecuada para educar a las personas Sordas. Ser "oralizado" quiere decir que la enseñanza y el aprendizaje se deben dar a través del habla, es decir, de la rehabilitación oral. La educación de la escuela oralista se centra en la

14 La principal diferencia entre las dos escuelas es la forma de comunicación. Mientras que la escuela oralista promueve la comunicación oral, la escuela gestualista promueve la comunicación a través de la Lengua de Señas.

15 Este era el lema de la primera institución que se encargó de la educación de niños sordos en Bogotá: el Instituto Nuestra Señora de la Sabiduría. lectura labio-facial para comprender el lenguaje oral. Así, se deben adoptar las medidas necesarias para lograr la oralización de las personas $y$, de esta manera, integrarlas en la comunidad oyente, puesto que la lengua de señas sola las aísla de la sociedad y las margina aún más.

Para Hurtado (2004), la escuela oralista está muy ligada con la mirada clínica que desde la década del siglo XX se le ha dado a las personas Sordas, una mirada a cargo especialmente de profesionales de la salud, psicólogos y pedagogos. Este pensamiento restringe la comunidad Sorda a un grupo de personas con una "limitación" en la capacidad auditiva, como "individuos aislados que culturalmente pertenecen a la sociedad oyente en la que nacen y, por lo tanto, se debe luchar por una oralización para poder integrarlos como seres normales" (p. 8).

\subsection{Escuela gestual o bilingüe}

Esta escuela considera que las personas Sordas son un grupo social y una comunidad cultural y lingüística, para quienes la mejor educación se da a través de la Lengua de Señas, en nuestro país, conocida como Lengua de Señas Colombiana (LSC). Si bien aún no existe consenso sobre si la Lsc debe ser considerada una lengua materna y el idioma nacional (en este caso el español) una segunda lengua, la escuela gestual aboga porque la ssc sea la lengua materna de la comunidad Sorda.

Los niños que adquieren la lengua de señas de manera natural muestran diferencias significativas a favor en cuanto a la resolución de proble- 
mas, comparados con los niños que han pasado por un proceso de oralización, ya que el lenguaje cumple una función regularizadora en los actos de pensamiento (Sánchez, 1992).

Ahora bien, para la escuela gestualista la comunidad Sorda no se diferencia de la comunidad oyente por una limitación o un déficit en la comunicación, sino por una forma de comunicación diferente, que se da a través de la Lsc. De ahí el ideal de establecer a la población Sorda como minoría lingüística. El artículo 2 de la Ley 324 de 1996 señalaba que "El Estado Colombiano reconoce la Lengua Manual Colombiana, como idioma propio de la Comunidad Sorda del País", pero dicho artículo fue declarado inexequible por la Corte Constitucional en sentencia C-280 de 2002, analizada más adelante.

El paradigma oralista, dominante por tanto tiempo en nuestro país, impidió el acceso de las personas Sordas a la lengua de señas y el debido desarrollo de esta como lengua. La educación bilingüe consiste en la formación integral en dos lenguas que se enriquecen y se desarrollan simultáneamente. Respecto de la comunidad Sorda se busca que la Lsc sea su primera lengua, y el castellano la segunda, acorde con la idea de la comunidad Sorda como minoría lingüística.

Asimismo, el bilingüismo permite una interacción entre las dos comunidades, lo que facilita que Sordos y oyentes aprendan mutuamente a través del apoyo y de la colaboración (Garzón, 2014). Como hemos visto, la población oyente ha determinado por mucho tiempo el sistema educativo de las personas Sordas, imponiendo una metodología ideal de aprendizaje. La comunidad Sorda no debería ser forzada a aprender de la misma manera que la población oyente y tampoco puede ser esta una justificación para que las dos comunidades no gocen de los mismos derechos y garantías en términos educativos.

Existen diferentes opiniones sobre este punto, algunas de ellas no necesariamente están en contra de la segregación, pues contemplan la posibilidad de estudiar en escuelas e instituciones únicamente para personas Sordas. Siendo el elemento transversal el problema lingüístico, se tiene que tener en cuenta que las lenguas se generan bajo condiciones comunitarias.

\section{Lengua de Señas Colombiana}

"En el idioma reside la principal arma de resistencia de aquellas culturas que durante siglos han sufrido la imposición de valores culturales que les son ajenos" Rigoberta Menchú Tum.

Esta parte pretende esbozar las características generales de la Lsc desde mi perspectiva personal como estudiante de V Nivel de Lsc en Fenascol y la ayuda de varios artículos sobre esta. Si consideramos que las personas Sordas pueden ser una minoría lingüística y cultural, "la lengua de signos se convierte en un factor elemental, no solo como herramienta de comunicación sino como factor de construcción, de identificación y de pertenencia de dicha minoría" (Cuenca, Palacios, Ramiro, De Asís y Barranco, 2012).

Como hemos mencionado, la construcción de la lengua de una comunidad, en este caso la LSc en la comunidad Sorda, juega un papel definiti- 
vo para su conformación como minoría lingüística y cuestiona la visión que equipara el lenguaje humano con el lenguaje oral. Según la subgerente de Educación Inclusiva en la Fundación Saldarriaga Concha, Diana Patricia Martínez (2014), debemos entender que el desarrollo del lenguaje está completamente relacionado con el desarrollo del pensamiento. En palabras de Buxó (1983) “la lengua es el subsistema cognitivo más importante de la cultura (...) es el código simbólico por excelencia de los significados culturales". Lo anterior quiere decir que la cultura se interioriza a través de la lengua y, a su vez, la lengua es una producción cultural e histórica. ${ }^{16}$ Aceptar la Lsc como una verdadera lengua es el primer paso para reconocer a la comunidad Sorda como minoría. Es necesario empezar a reevaluar creencias referentes a las lenguas de señas en general, como por ejemplo que estas son medios insuficientes para hablar de nociones abstractas y para la expresión de metáforas, ironía y humor (Castellanos, 2010). Para más información ver la tabla 5.

Ahora bien, es importante aclarar que la Lsc no es un español signado, es decir, que a cada palabra le corresponda una seña. ${ }^{17}$ Cuando se es-

16 Para mayor detalle ver la teoría del relativismo lingüístico propuesta por Edward Sapir y Benjamin Lee Whorf (conocida comúnmente como la hipótesis Sapir-Whorf).

17 Por ejemplo, en la LSc no existen los verbos "ser" y "estar", pues estos se encuentran incluidos en la oración, así como no existen preposiciones ni conjunciones como "y" "e" y "de". Los pronombres personales se expresan señalando a las personas directamente. En caso de que las personas no se encuentren presentes la seña se hace hacia un punto imaginario. Sin embargo, las señas del pronombre posesivo se diferencian de las del pronombre personal en que las primeras se realizan de una forma más fuerte e intensa. Asimismo, los pronombres pronominales en la Lsc están dados por la dirección del verbo y de acuerdo con la posición en que se encuentren las personas. De esta manera, si yo quiero decir "te pregunto" realizo la tudia la Lsc se entiende que la lengua tiene una estructura propia y que no es una simple traducción del español a símbolos manuales. ${ }^{18}$ Asimismo, se debe tener en cuenta que la Lsc no es una lengua manual, pues está compuesta por varias expresiones corporales -principalmente de la parte superior del cuerpo-y faciales. ${ }^{19}$

Si bien es cierto que hoy en día tenemos bastante material con vocabulario de señas, no podemos hablar de una total estandarización. El problema no se limita únicamente a diferentes regiones, incluso en la misma zona geográfica y en la misma institución de enseñanza no hay señas estandarizadas. He tenido la oportunidad de recibir clase de distintos profesores, todos ellos miembros de Fenascol, y entre ellos mismos algunas de las señas son diferentes. Este ha sido un problema para la comunidad Sorda y para el aprendizaje de señas por parte de la comunidad oyente.

Vale la pena tener claro que, de acuerdo con la forma de comunicación que se adopte, las personas Sordas pueden ser clasificadas en se-

seña de "preguntar" en dirección a la persona, pero si quiero decir "pregúntame" realizo la seña de "preguntar" en dirección hacia mí.

18 Un ejemplo puede ser la organización de la frase cuando se hacen preguntas. En la Lsc la palabra interrogativa siempre debe ir al final, puesto que así la pregunta es mucho más clara para la persona Sorda, explica Moyano (2014), quien es tecnólogo en administración de mantenimiento de computadores y persona sorda. Así, en español diríamos: ¿cuántos años tienes?, y la traducción de señas a español de la misma pregunta sería: ¿tu años cuántos?

19 Un ejemplo son los pronombres interrogativos, que deben ir acompañados de la expresión facial o corporal adecuada; generalmente se fruncen las cejas y los hombros se van hacia delante cuando se quiere hacer una pregunta. La expresión facial es sumamente importante a la hora de intentar comunicar un mensaje y es necesaria cuando se habla de ciertas cosas como cantidad y tamaño — cuando se dice que algo es pequeño, los ojos se entrecierran y se frunce la nariz-, por eso se dice que la Lsc es una lengua espacial. 
ñantes, semilingües o hablantes. La situación comunicacional de cada uno de estos grupos varía y depende de ciertos elementos, por ejemplo, del momento en que se adquiere la sordera: infancia, niñez, adolescencia o adultez.

Generalmente, los padres que deciden oralizar a sus niños Sordos adoptan varias medidas para lograrlo y rechazan el aprendizaje de la LSc como primera o segunda lengua. Aunque la situación puede variar según los elementos que he mostrado, "si el menor no es estimulado por la interacción de una lengua que le sea naturalmente accesible (...) se puede dificultar cualquier esfuerzo ulterior de desarrollo cognoscitivo general, así como de adquisición de un lenguaje natural" (Birdsong, 1999).

Además de esto, y según varios autores, cuando el niño Sordo empieza a desarrollar una mayor capacidad para vocalizar, esto tiende a retrasar la aceptación de su condición de persona Sorda tanto por sus padres como por él mismo. Lo que ha sucedido en varios casos es que los niños no señantes no se adaptan completamente a ninguna de las dos comunidades - Sorda y oyentey su proceso de desarrollo cognitivo y social se ve disminuido.

Finalmente, las personas que cuentan con implante coclear, en la mayoría de casos no se ponen en contacto con la lengua de señas de su comunidad. Según la Federación Alemana de Sordos (2006), "cuando un niño sordo crece en un entorno bilingüe, con la lengua hablada y la de señas, se le garantiza una comunicación plena en $100 \%$ tanto si el implante coclear o el au- dífono provistos terminan teniendo éxito o no". Diferentes estudios científicos han demostrado que hay niños implantados que en sus primeros años de vida no evidencian desarrollo cognitivo ni un lenguaje oral, y solo desarrollan parcialmente el lenguaje y el conocimiento cuando se les pone en contacto con la lengua de señas. Igualmente, y según el mismo estudio, las personas Sordas educadas en programas bilingües tienen una competencia lectora y de comprensión muy cercana a la de los niños oyentes. De igual modo, estas personas demuestran una mayor satisfacción en sus vidas que aquellas que solo han sido educadas en contextos exclusivamente orales.

Además de los riesgos en la salud que el implante coclear puede generar, el éxito no está tampoco asegurado. De todas formas, con el tiempo la implantación se promueve cada vez más y a edades más tempranas, sin que se brinde una información completa a las personas Sordas y a sus familias sobre los riesgos y los medios alternativos, tales como el uso de la lengua de señas.

Considero que el estudio juicioso de la Lsc es un factor esencial para hablar de la educación de niños y adultos Sordos y para proponer las mejores estrategias para la inclusión educativa de esta comunidad. Reconocer la lengua de señas mejorará la calidad de vida de esta población y, además, será un paso más para su integración social, puesto que constituirse como comunidad lingüística minoritaria le significaría ocupar una posición definida en la sociedad. 


\section{La educación superior \\ "Con la educación, las personas transforman \\ el contexto social \\ y a su vez son transformadas por éste, \\ en una interacción \\ que se alimenta continuamente"}

(Sarmiento, 2010).

A través de la educación la sociedad se desarrolla, se transforma, genera conocimientos, forja valores y modifica sus comportamientos. La educación ayuda en la formación de nuestra conciencia individual, de nuestra autodeterminación, de nuestra autonomía y de las interacciones individuales y grupales que realizamos como seres humanos. De ahí la importancia de encaminar nuestros esfuerzos a fortalecer las políticas públicas en educación que garanticen a cabalidad este derecho fundamental. Sin duda, el sistema educativo de nuestro país no está funcionando de una manera óptima, ${ }^{20}$ lo que se evidencia en los niveles de pobreza e inequidad de las poblaciones más vulnerables. El derecho a la educación no está cumpliendo con la mejor calidad para todos y cada uno de los colombianos, lo que produce aún más desigualdades y violaciones de derechos humanos.

Según Sarmiento (2010), la educación en CoIombia debe cumplir con ciertas características que aseguren que el acceso a esta sea realmente efectivo:

20 Lo anterior se puede evidenciar, por ejemplo, en los resultados de 2014 de las pruebas PISA (Programa Internacional de Evaluación de Estudiantes), en donde Colombia ocupó el último lugar entre 44 países. i. Disponibilidad y acceso: se mide en términos de cupos y programas de enseñanza en todo el territorio nacional, con especial énfasis en las poblaciones históricamente vulneradas. Asimismo, se tiene en cuenta la infraestructura física de las instituciones educativas y centros de enseñanza y la disponibilidad de profesores.

ii. Calidad: cumplimiento de los estándares de calidad fijados por el Ministerio de Educación Nacional. Este factor se mide principalmente a través de las pruebas de calidad realizadas periódicamente por el Estado.

iii. Permanencia: verificar que se den las condiciones necesarias para que los estudiantes no deserten a lo largo de sus estudios, es decir, que los sistemas educativos cuenten con alternativas eficaces para lograr la enseñanza de los grupos más vulnerables.

Aunque esta investigación intenta analizar el acceso de la población Sorda a la educación superior específicamente, no puede dejar a un lado la situación actual sobre el acceso a la educación básica y media, pues son las puertas para poder entrar a la educación superior. ${ }^{21}$

Ahora bien, en relación con la educación superior de las personas con discapacidad, el MEN en el 2008 registró 24.043 instituciones educativas formales, de las cuales solo el $27,8 \%$ informan sobre matrícula de esta población. Según dicho Ministerio, en Bogotá hay un total

$21 \quad$ Ver anexo, tablas 6 y 7. 
de 2438 instituciones educativas, de las cuales 601 tienen personas con discapacidad, es decir, un 24,7\%; respecto a sedes educativas, 800 ofertan cupos para personas con discapacidad frente a 1973 que no lo hacen, lo que significa que el porcentaje de sedes aptas para personas con discapacidad es del $28,8 \%$;22 del total de sedes educativas solo 594 informan tener modelo pedagógico para la atención de personas con discapacidad, y del total de la matrícula las personas con discapacidad representan un 0.9\%, es decir, 12.008 personas.

Lo anterior evidencia dos problemas fundamentales: i) Según Martínez (2014) uno de los problemas más grandes es que las universidades no tienen presupuestado en ninguna parte el apoyo específico para las personas con discapacidad y; ii) Colombia es un país que no tiene un sistema educativo totalmente estatal y la calidad no está unificada por regiones y zonas. Esto hace que existan más dificultades para el acceso a la educación superior, pues las personas no tienen el mismo nivel académico aunque se encuentren en el mismo nivel educativo (Collazos, 2014).

22 En el estudio realizado por el MEN no se especifica a qué se refieren con "tener oferta para personas con discapacidad" ni qué se entiende por institución "apta". No es claro si se trata de instituciones que tienen programas únicamente para personas con discapacidad o que cuentan con una infraestructura accesible, etc.

\section{E. Educación superior inclusiva}

"Se ha demostrado que la educación inclusiva, derecho de todos y todas, al promover la convivencia con la diferencia y lo plural, impulsa la superación de estereotipos, de prejuicios y, por ende, de la discriminación" (Informe para la Comisión Interamericana de Derechos Humanos, 2009)

Hasta el momento, las cifras que hemos analizado denotan una persistente y alarmante situación de exclusión de las personas con discapacidad del sistema educativo. Los Estados deben adoptar las medidas que sean necesarias para garantizarle a la población con discapacidad su derecho a la educación, no solo en términos de acceso sino también de permanencia. Todo lo anterior es posible a través de un sistema de educación que sea inclusivo, que atienda los ajustes requeridos para responder a las necesidades particulares de los estudiantes, que promueva el valor de la diferencia, que no permita la discriminación y que garantice la igualdad.

La inclusión no es solo un deber o una obligación que tenemos como sociedad con las poblaciones históricamente vulneradas. Vivir y enseñar teniendo como fundamento la diversidad y la pluralidad nos ayuda a promover de una manera directa el pleno desarrollo de las personas y el respeto por los derechos humanos. Para el guía intérprete Ricardo Becerra (2014) “la inclusión debe ser equitativa, es muy importante trabajar con visión global y enfoque diferencial, es decir, reconocer la necesidad que tiene cada 
cual equitativamente, lo que significa satisfacer la necesidad de las personas a nivel particular".

Durante las últimas décadas se han logrado varios avances importantes para acercarnos e introducir en nuestras políticas el concepto de educación inclusiva. El término ha evolucionado de educación especial a educación integrada y finalmente a educación inclusiva. La educación inclusiva promueve que los cambios o ajustes razonables, necesarios para atender las necesidades individuales de los estudiantes, los realicen las instituciones y no al revés.

Para Martínez (2014), la inclusión no solo debe ser entendida desde la mirada de la discapacidad, "cuando yo hablo de inclusión hablo de participación efectiva; a través de la inclusión logramos tener una participación efectiva en el entorno, pero dicha participación solo se logra si el entorno no se transforma, lo que se traduce en apoyos, o como lo dice la Convención: ajustes razonables". La visión de Carlos Parra ${ }^{23}$ (2014) sobre la importancia de la educación inclusiva también es interesante: "la educación inclusiva es un "gana-gana" por los dos lados, uno porque una persona con discapacidad se relaciona con personas sin discapacidad y va generando hábitos y conoce la cultura social en general, y dos, la gente que no tiene discapacidad aprende a apreciar la diversidad".

El párrafo 2 del artículo 13 de las Observaciones generales adoptadas por el Comité de Derechos

23 Doctor en derechos fundamentales. Especialista en derecho constitucional. Abogado de la Universidad del Rosario. Trabajó en la construcción de la Ley 1618 de 2013.
Económicos, Sociales y Culturales, distingue cuatro dimensiones del derecho a la educación inclusiva que deben ser tenidos en cuenta:

1. Disponibilidad: la cantidad de instituciones y programas educativos debe ser suficiente. Este aspecto incluye varios elementos como: infraestructura, agua potable, docentes calificados, materiales, bibliotecas, entre otros.

2. Accesibilidad: las instituciones y los programas de enseñanza deben ser accesibles para todos sin discriminación alguna. Este elemento consta de tres factores más:

i) No discriminación

ii) Accesibilidad material (geográficamente o a través de tecnología moderna)

iii) Accesibilidad económica.

3. Aceptabilidad: los programas de estudio y los métodos pedagógicos deben ser aceptables, es decir, pertinentes, adecuados culturalmente y de buena calidad.

4. Adaptabilidad: la educación debe ser flexible, esto es, que se ajuste a las necesidades específicas de las comunidades y sociedades y de los alumnos considerados individualmente.

Estos cuatro elementos deben ser incluidos en las políticas de educación inclusiva, pues no se trata de "incluir por incluir", sino que se debe contar con los ajustes y apoyos requeridos por cada estudiante. De lo contrario, el efecto podría ser inverso: los estudiantes integrados y no 
incluidos pueden terminar por ser aislados o, en el peor de los casos, desertando de la institución educativa.

No se puede decir que sea fácil el proceso de inclusión, evidentemente implica una serie de desafíos, pero estos pueden ser enfrentados no a través de la idea de limitaciones de las personas con discapacidad, sino de sus habilidades y potenciales. Es, pues, necesario que como país consideremos la educación inclusiva como un elemento inherente a la educación como tal, pues hacerlo nos va a permitir reformular las directrices adecuadas sobre la legislación y las políticas públicas. En palabras de Collazos (2014), "la inclusión no es poner a un muchacho sordo con unos oyentes en un salón, ni tampoco decir que el profesor sabe unas señas, se necesitan condiciones reales para que la educación sea de calidad como para los otros".

Como funcionario del mEN, Garzón Gil (2014) explica:

en educación superior hemos logrado en los últimos diez años el acceso de experiencias de personas Sordas a un nivel un poco más amplio que en los años anteriores. Realmente antes de los años 2000, por la década de los 90, teníamos en el país muy pocos casos de personas sordas en la educación superior. Aunque no tenemos datos precisos, sabemos que teníamos algunas personas sordas ya que el INSOR y la comunidad sorda en Bogotá es una comunidad minoritaria, eso hacía que fácilmente se pudieran reconocer las personas sordas que estaban en la educación superior.

Por esta razón, prosigue, el Ministerio considera que es difícil conceptualizar la integración en el caso de la educación superior -a diferencia de la educación básica y media- y que es mejor enfocarse en cada caso puntual.

El concepto de inclusión desarrollado por el MEN se ha usado más en la educación básica y media. Sin embargo, este Ministerio empieza a hablar de la inclusión enfocada en la diversidad, teniendo en cuenta elementos como el acceso y la permanencia. En palabras de Garzón Gil (2014):

No se puede entender que pasamos de un concepto de integración a inclusión, sino comprendiendo más bien la particularidad del nivel terciario en nuestro país (...) se está consolidando una política de atención específica para sordos, política de atención a la diversidad con un enfoque diferencial que pueda darle los elementos que requiere para que la persona sorda en particular permanezca en el sistema.

Para el MEN, la educación inclusiva debe ser entendida como una estrategia central para luchar contra la exclusión social, es decir, para desafiar un proceso multidimensional caracterizado por factores económicos, políticos y jurídicos, y por factores simbólicos y subjetivos. Según los Lineamientos de política de educación superior inclusiva (MEN, 2013), el cambio en la concepción de la educación superior a nivel mundial implica necesariamente cambios en las políticas, en las mentalidades, en las ofertas y en las prácticas educativas, esto con el fin de que "los sistemas educativos efectivamente sean promotores y facilitadores del educar y del aprender apelando a la diversidad de ambientes, ofertas y procesos de aprendizaje". Bajo esta óptica, la 
inclusión no se debe entender solamente como la provisión de infraestructura y tecnologías para garantizar el acceso a ciertos estudiantes. Hoy en día, la educación inclusiva es una política pública que obliga al cuestionamiento de los esquemas de organización tradicionales en los que se ha basado siempre la educación -contenidos, asignaturas, práctica docente, entre otros aspectos-.

Paralelamente, el MEN se refiere a las seis características intrínsecas del concepto de educación inclusiva, obtenidas después de una investigación y comparación de las definiciones existentes: participación, diversidad, interculturalidad, ${ }^{24}$ equidad, pertinencia y calidad, las cuales se articulan entre sí y son fundamentales para lograr este propósito. Basándose en estas características, desarrolló junto con el Centro de Investigaciones para el Desarrollo de la Universidad Nacional de Colombia, un estudio sobre las condiciones de acceso, permanencia y graduación del sistema educativo. ${ }^{25}$

En la actualidad, la inclusión de los estudiantes Sordos en las instituciones de educación superior es muy precaria. Collazos (2014) asegura que las universidades públicas empezaron con programas de inclusión para personas con discapacidad con un alto costo económico, por la integración de intérpretes en las aulas y las dife-

24 Interculturalidad entendida como el "Conjunto de relaciones entre diferentes grupos culturales que conduce a un proceso dialéctico de constante transformación, interacción, diálogo y aprendizaje de los diferentes saberes culturales en el marco del respeto" (Ministerio de Educación Nacional, 2013).

Ver en el anexo las tablas 8,9 y 10 rentes luchas internas entre profesores y directivas que estaban o no de acuerdo. A mi parecer, lo anterior evidencia un sistema educativo que muestra todavía a las personas con discapacidad como no productivas para la sociedad y, por tanto, como la peor inversión posible. Ejemplificando el pago de intérpretes para las personas sordas, Jaime Collazos (2014) afirma que "en un sistema como el nuestro, cualquier proceso de inclusión que le genere a su dueño privado un gasto adicional no lo va a hacer, este es un sistema de libre comercio, yo no puedo poner un negocio para que me digan que voy a perder". Es importante que se resuelvan algunos temas económicos y de recursos para el financiamiento de los intérpretes que requieren como apoyo las personas sordas, pues la inversión económica es muy alta.

Es un gran problema también que las propuestas educativas del Estado se basen en un desconocimiento de la misma comunidad sorda, lo que tiene una incidencia directa en los procesos educativos. Los maestros regulares no tienen formación o conocimientos suficientes sobre la LSc, sobre las personas sordas, sobre la diversidad en aula y sobre metodologías y estrategias didácticas y pertinentes para esta población. Esto hace que la dinámica del día a día sea muy compleja, haciendo que los resultados no sean los más pertinentes (Garzón, 2014).

\section{MARCO JURÍDICO REGULATORIO}

Colombia ha integrado en su ordenamiento diferentes instrumentos jurídicos que buscan re- 
conocer la dignidad y los derechos de las personas con discapacidad, así como la necesidad de garantizarles que puedan ejercer dichos derechos plenamente y sin discriminación alguna. A continuación se analizan estos instrumentos, para poder realizar un examen final sobre las fortalezas y debilidades del marco regulatorio en relación con el ordenamiento jurídico colombiano y respecto de la educación inclusiva de la comunidad sorda del país.

\section{A. Instrumentos jurídicos internacionales}

Según el artículo 93 de nuestra Constitución Política, los tratados y convenios internacionales ratificados por Colombia que reconozcan derechos humanos, prevalecen sobre el orden interno. El bloque de constitucionalidad comprende las normas y los principios que, aunque no aparezcan en el texto constitucional, son utilizados como parámetros de control de constitucionalidad y se entienden integrados a la Carta como verdaderos principios y reglas de valor constitucional (sentencia, C-067 de 2003). A continuación se examinan los instrumentos jurídicos internacionales que de alguna manera se relacionan con personas sordas y con educación superior.

\section{Convención sobre los Derechos de las Personas con Discapacidad de las Naciones Unidas}

“la entrada en vigor de la Convención llena un vacío importante en materia de protección en las normas internacionales de derechos humanos"

(Oficina de Alto Comisionado de las Naciones

Unidas, 2011).

La Convención sobre los Derechos de las Personas con Discapacidad (CDPD) "es el primer tratado en materia de derechos humanos que detalla de forma exhaustiva todos los derechos de las personas con discapacidad y clarifica las obligaciones de los Estados de respetar, proteger y hacer cumplir esos derechos" (Naciones Unidas, 2011).

Sin duda, la Convención logra llenar un vacío muy grande en materia de protección de los derechos humanos generando un gran impacto en las legislaciones, las políticas públicas, las prácticas sociales y las prácticas estatales. Con la adhesión a la Convención, nuestro país adquirió la obligación de asegurar y promover el pleno ejercicio de todos los derechos humanos y libertades fundamentales de las personas con discapacidad, así como promover el respeto por la dignidad humana.

Así, la Convención es el principal instrumento jurídico que debe ser utilizado en nuestro país cuando estemos frente a casos de discriminación por motivos de discapacidad. En ella, los Estados Partes se obligan a realizar y adoptar 
las medidas necesarias (jurídicas, administrativas y legislativas) para poder hacer efectivos los derechos allí plasmados, así como a tomar las medidas oportunas -incluidas las legislativaspara derogar o modificar leyes, reglamentos, costumbres y prácticas existentes que constituyan discriminación contra las personas con discapacidad (artículo 4).

Paralelamente, es importante tener en cuenta la definición que ha dado la Convención sobre ajustes razonables:

Por "ajustes razonables" se entenderán las modificaciones y adaptaciones necesarias y adecuadas que no impongan una carga desproporcionada o indebida, cuando se requieran en un caso particular, para garantizar a las personas con discapacidad el goce o ejercicio, en igualdad de condiciones con las demás, de todos los derechos humanos y libertades fundamentales.

Estas modificaciones del entorno se deben generar principalmente, porque los elementos o mecanismos de acceso y diseño universal son insuficientes. Así, los ajustes razonables terminan siendo la forma de garantizar el derecho a la igualdad de oportunidades de las personas con discapacidad, teniendo en cuenta que su no realización debe ser considerada como discriminación.

Asimismo, el artículo 9 de la Convención se refiere a la accesibilidad y estipula que con el fin de que las personas con discapacidad puedan vivir en forma independiente, "Ios Estados Partes adoptarán medidas pertinentes para asegurar el acceso de las personas con discapacidad, en igualdad de condiciones con las demás, al entorno físico, el transporte, la información y las comunicaciones". La Convención es clara al afirmar que estas medidas, para ser implementadas, deben incluir la identificación y eliminación de todos los obstáculos y barreras de acceso. $Y$ al establecer que deben ser aplicadas, entre otras cosas, a los servicios de información y de comunicación, hace alusión directa a la comunidad Sorda, y asegura que el derecho a acceder a la información debe hacerse según la forma de comunicación, lo que implica que se debe aceptar, facilitar, reconocer y promover, entre otros modos, la utilización de la lengua de señas. Además, que se debe reconocer y apoyar la identidad cultural y lingüística específica de la cultura de las personas sordas.

En lo referente a la educación, la cDPD obliga a los Estados Parte a asegurar un sistema de educación inclusiva en todos los niveles de enseñanza, a través de la implementación de los ajustes razonables que sean necesarios en función de las necesidades individuales. La Convención deja claro que los Estados Partes, con el fin de propiciar la participación plena y en igualdad de condiciones a la educación, deberán adoptar las medidas que sean pertinentes, entre ellas:

b) Facilitar el aprendizaje de la lengua de señas y la promoción de la identidad lingüística de las personas sordas;

c) Asegurar que la educación de las personas, y en particular los niños y las niñas ciegos, sordos o sordociegos se imparta en los lenguajes y los modos y medios de comunica- 
ción más apropiados para cada persona y en entornos que permitan alcanzar su máximo desarrollo académico y social.

Entre las medidas de inclusión, la Convención precisa el empleo de maestros cualificados en lengua de señas o en escritura braille, junto con el uso de técnicas y materiales educativos, con el fin de contribuir a hacer efectivo este derecho a las personas con discapacidad, y asegurar que tengan acceso a la educación superior y a la formación profesional en igualdad de condiciones (incisos 4 y 5 del artículo 24).

Es evidente que la CDPD entiende que el derecho a la educación es un elemento esencial para que las personas con discapacidad puedan gozar de todos sus derechos humanos y libertades fundamentales. En concordancia, tanto el Estado colombiano como sus establecimientos educativos tienen la obligación de promover la inclusión educativa de las personas con discapacidad y de eliminar las barreras jurídicas que impidan su acceso y permanencia en el sistema educativo.

\section{Otros instrumentos internacionales de derechos humanos ${ }^{26}$}

Junto con la CDPD existen otros instrumentos jurídicos internacionales que garantizan los dere- chos de las personas con discapacidad. El Pacto Internacional de Derechos Económicos, Sociales y Culturales de las Naciones Unidas (PIDESC, 1976), las Observaciones Generales del Comité de Derechos Económicos, Sociales y Culturales n. ${ }^{\text {s }} 5$ y 13 y la Convención Interamericana para la Eliminación de todas las Formas de Discriminación contra las Personas con Discapacidad, comparten varias fortalezas que deben ser resaltadas:

- El tener como base el reconocimiento de la dignidad humana y los derechos iguales e inalienables de las personas con discapacidad.

- El reconocer la educación como un derecho de todas las personas y resaltar su valor e importancia, pues se le considera un "derecho humano intrínseco y un medio indispensable para realizar otros derechos humanos" (Observación General n. ${ }^{\circ}$ 5). Asimismo, la educación es vista como el principal medio para salir de la pobreza, participar plenamente en la comunidad y promocionar los derechos humanos.

- El establecer que es obligación primordial de Ios Estados abogar porque se garantice el acceso a la educación por cuantos medios sean necesarios. ${ }^{27}$

27 Según la Observación n. ${ }^{\circ} 15$, los Estados Partes tienen tres tipos de obligaciones que deben cumplir: i) Obligaciones de respetar: se deben evitar medidas que de alguna manera dificulten e impidan el disfrute del derecho a la educación; ii) Obligación de proteger: los Estados deben adoptar medidas que eviten que el derecho sea obstaculizado por terceros; y iii) Obligación de cumplir (que incluye la obligación de facilitar y de proveer): los Estados deben adoptar medidas positivas que faciliten a los individuos y a las comunidades el derecho a la educación. 
- La obligación de no discriminar por motivos de discapacidad. La discriminación no necesariamente se tiene que dar de forma directa, los instrumentos amplían la noción de discriminación a formas más sutiles: negligencia, segregación, exclusión, separación y distinción. Se reconoce que los efectos de estas formas de discriminación han sido particularmente graves en campos como el de la educación. Su prohibición y la adopción de medidas para erradicarlas son de aplicación inmediata, y no pueden estar supeditadas a una implementación gradual ni a la disponibilidad de recursos.

- Siendo uno de los objetivos principales de estos instrumentos la prevención y la eliminación de todas las formas de discriminación en contra de las personas con discapacidad, para propiciar su integración plena en la sociedad, no solo reconocen que existen varios tipos de obstáculos, sino que amplían el espectro tradicional (obstáculos arquitectónicos) y empiezan a hablar de obstáculos comunicacionales y actitudinales.

Sin embargo, y aunque estos instrumentos representan grandes avances en materia de reconocimiento de derechos a las personas con discapacidad, tienen varias debilidades que deben ser identificadas:

- Solo la Observación n. ${ }^{\circ} 13$ se refiere específicamente a la educación superior, el resto definen este derecho de una manera general y abstracta, sin pormenorizar las obligaciones particulares respecto a este nivel educativo.

- El lenguaje utilizado por los instrumentos sigue siendo peyorativo hacia las personas con dis- capacidad. Varios apartes contienen palabras como "deficiencia”, “limitación”, “especial”, "desfavorecido", términos que evidencian que la discapacidad sigue siendo vista a través de una óptica de limitación y déficit que sitúa a las personas con discapacidad en un nivel inferior al de las demás. Es muy difícil lograr cambios profundos en una sociedad que cuenta todavía con instrumentos jurídicos redactados en un lenguaje en sí mismo discriminador. ${ }^{28}$

- Varios de los instrumentos tienen como tareas principales la “prevención”, "rehabilitación” y “detección temprana de la discapacidad", Io que demuestra que todavía existen rezagos del modelo médico de discapacidad, pues al intentar "prevenir" se sigue dando connotaciones negativas a la discapacidad, y asumiendo conceptos de "normalización" errados. La detección temprana podría ser importante en materia de recopilación de datos y de identificación de la diversidad de la comunidad, con el ánimo de encaminar las políticas públicas necesarias para garantizar los derechos de las personas, pero no para identificar a las personas y empezar su tratamiento o rehabilitación, pues nuevamente retrocedemos a la idea de normalización que va en contravía de los derechos de las personas con discapacidad.

28 Por ejemplo, las Observaciones Generales del Comité de Derechos Económicos, Sociales y Culturales n. ${ }^{\circ} 5$ y 13 y la Convención Interamericana para la Eliminación de todas las Formas de Discriminación contra las Personas con Discapacidad. 


\section{B. Instrumentos jurídicos nacionales}

\section{Constitución Política de Colombia}

La Constitución Política consagra uno de los pilares de nuestro ordenamiento jurídico: el derecho a la igualdad (artículo 13). Además, establece la educación como un derecho de la persona (artículo 67), reconocido jurisprudencialmente en varias ocasiones como derecho fundamental. A continuación se analizan estos derechos brevemente bajo la óptica de las personas con discapacidad, específicamente de las personas sordas, por considerar que son los derechos que se les vulneran cuando se les niega el acceso a la educación superior.

\subsection{Sobre el derecho a la igualdad}

El artículo 13 de la Constitución sostiene:

Todas las personas nacen libres e iguales ante la ley, recibirán la misma protección y trato de las autoridades y gozarán de los mismos derechos, libertades y oportunidades sin ninguna discriminación por razones de sexo, raza, origen nacional o familiar, lengua, religión, opinión política o filosófica.

El Estado promoverá las condiciones para que la igualdad sea real y efectiva y adoptará medidas en favor de grupos discriminados o marginados.

El Estado protegerá especialmente a aquellas personas que por su condición económica, física o mental, se encuentren en circunstancia de debilidad manifiesta y sancionará los abusos o maltratos que contra ellas se cometan.
En su obra Los derechos fundamentales en la Constitución de 1991, Manuel José Cepeda (1997) analiza seis elementos presentes en el artículo 13, que se resumen a continuación:

1. Principio General. Reúne tres conceptos diferentes bajo una mirada integral de la igualdad:

i) Igualdad ante la ley, es decir, que todas las leyes se aplican de igual manera para todos y nadie puede invocar privilegios para solicitar que estas no se le apliquen (concepción puramente formal);

ii) Igualdad de trato, esto es, que "no se establezcan clasificaciones que no sean razonables, objetivas y fundadas en fines legítimos, teniendo en cuenta siempre la realidad" ( $p$. 87). Así, es necesario determinar en qué momento estamos frente a criterios de diferenciación válidos, cuándo se pueden usar en condiciones especiales y cuándo están excluidos completamente del ordenamiento, esto a través de diferentes criterios de evaluación (aspecto sustancial de la igualdad).

iii) Protección igual por parte de las autoridades (legislativas, judiciales y administrativas), quienes "deben tener el impacto real de la norma frente a los distintos grupos e individuos, para dar así protección igual a quienes se encuentran en igualdad de circunstancias" (p. 87). 
2. Prohibición de discriminación. ${ }^{29}$ Varios criterios de discriminación han sido prohibidos por instrumentos internacionales y por la legislación de diferentes países, entre ellos la raza, el género, la nacionalidad, la lengua. El segundo elemento de la norma prohíbe que se discrimine (que se otorguen privilegios, que se niegue el acceso a beneficios, que se restrinja el ejercicio de un derecho a un determinado individuo o a un grupo de personas) de manera arbitraria e injustificada. Paralelamente, es importante tener presente que no cualquier distinción es una discriminación que termina por vulnerar el derecho a la igualdad. La discriminación se debe enmarcar dentro de todos los parámetros que se mencionaron anteriormente y recae sobre los jueces la tarea de determinar cuándo este tipo de diferenciaciones son o no constitucionales.

\section{El deber del Estado de promover condiciones} para lograr la igualdad real y efectiva. Este elemento se refiere esencialmente a la obligación que tiene el Estado de hacer, y no simplemente de abstenerse de discriminar. En varias ocasiones la jurisprudencia ha hecho referencia a la necesidad de que la igualdad sea real y efectiva. De ahí que se deban adoptar las medidas necesarias para favorecer grupos discriminados o marginados históricamente -como lo es la población con discapacidad-. La igualdad material está encaminada a hacer real en la práctica este derecho, es decir, modificar las circunstancias que im-

29 Cepeda (2007) entiende la discriminación como el hecho de "causarle perjuicios a un individuo o grupo de individuos teniendo en cuenta criterios que en realidad esconden prejuicios sociales y culturales". pidan a las personas el ejercicio pleno de sus derechos y el acceso a las oportunidades.

4. La posibilidad de conceder ventajas a grupos discriminados o marginados. La posibilidad de adoptar medidas a favor de grupos discriminados - como la población con discapacidad-, se fundamenta en la idea de este tratamiento diferenciado que "tiende a remediar la situación desventajosa en que se encuentran, promueve el surgimiento de nuevos valores que impidan que en el futuro se les continúe discriminando y garantiza su acceso a determinados foros de decisión, lugares de capacitación o en general, a aquellos beneficios que en condiciones ordinarias no estarían a su alcance" (p. 89).

5. Especial protección a personas que por su condición económica, física o mental se encuentren en circunstancias de debilidad manifiesta. Complementa el cuarto elemento puesto que le da cimiento al deber de protección exclusivo del Estado respecto de algunas personas que por su condición (según el artículo la condición puede ser económica, física o mental) se consideran beneficiarias. Respecto a esto, la Corte Constitucional ha afirmado:

Con el trato diferencial positivo se aplica la filosofía esencial del Estado Social de Derecho, que se traduce en el deber del Estado de proteger a las personas que por su condición económica, física o mental, se encuentren en circunstancias de debilidad manifiesta, para hacer que la igualdad sea real y efectiva. El principio de igualdad y la posibilidad de reali- 
zar el Estado una diferenciación positiva tienen como fundamento el Preámbulo de la Constitución, cuando éste se refiere al propósito de asegurar la igualdad dentro de un marco social justo (sentencia T- 330 de 1993).

6. La sanción de abusos y maltratos que se cometan contra personas en circunstancias de debilidad. Finalmente, la norma se refiere a las sanciones que se podrán imponer a las personas que abusen o maltraten a quienes se encuentren en situación de debilidad manifiesta. Sin embargo, y como lo afirma el autor, la norma no especifica qué tipo ni cuáles sanciones se deben aplicar.

El artículo en comento consagra la igualdad como derecho fundamental de nuestro ordenamiento jurídico, basado en el principio de dignidad que tenemos todos por el hecho de ser personas. Asimismo, como hemos visto, el Estado debe adoptar las medidas que resulten indispensables para igualar las condiciones de las personas con discapacidad a las del resto de ciudadanos, de modo que permitan su integración en la sociedad. Las razones que impidan el acceso a la educación superior no pueden ser, de ninguna manera, la situación de discapacidad en que se encuentre una persona.

\subsection{Sobre el derecho a la educación}

Según el artículo 67 de la Constitución Política "La educación es un derecho de la persona y un servicio público que tiene una función social; con ella se busca el acceso al conocimiento, a la ciencia, a la técnica, y a los demás bienes y valores de la cultura". El derecho a la educación es un derecho fundamental por conexidad, tal y como lo ha establecido la jurisprudencia de la Corte Constitucional, y por tanto de aplicación inmediata cuando la amenaza o vulneración del derecho a la educación apareja la amenaza o vulneración de otro derecho de carácter fundamental, como la igualdad, el libre desarrollo de la personalidad o el debido proceso.

La jurisprudencia de la Corte Constitucional ha establecido ciertos escenarios donde la vulneración de este derecho afecta derechos fundamentales. Uno de ellos "cuando se vulnera el derecho a la igualdad de acceso o de permanencia en el sistema educativo, o cuando el estudiante es discriminado por una institución educativa". Además, como lo ha contemplado dicha Corporación, el derecho a la educación se concreta principalmente "en la posibilidad de acceder al servicio público de educación". ${ }^{30}$

Finalmente, respecto a la educación como servicio público, la Corte Constitucional ha señalado que es deber estatal asegurar la prestación eficiente de los servicios públicos a todos los habitantes del país, pues es esta una finalidad social del Estado, como lo establece el artículo 365 de la Constitución: “serán prestados por el Estado, directa o indirectamente, por comunidades organizadas, o por particulares. En todo caso, el Estado mantendrá la regulación, el control y la vigilancia de dichos servicios".

30 Algunos ejemplos de sentencias de la Corte Constitucional que se refieren a la educación como un derecho fundamental y un servicio público con función social son: T-429 de 1992, T-329 de 1997, T-513 de 1999, T-620 de 1999, T-826 de 2004, T-170 de 2007 y T-487 de 2007. 


\section{Legislación, decretos y resoluciones}

Después de realizar un análisis crítico sobre la legislación existente en nuestro país que involucra disposiciones sobre el acceso y permanencia en la educación superior de las personas sordas, ${ }^{31}$ podemos identificar varios avances y falencias. A continuación se presentan las fortalezas:

- La noción de discapacidad empieza a tener cambios importantes a la vez que la legislación avanza con el tiempo. El concepto "situación de discapacidad" se acerca cada vez más al modelo social de discapacidad, por considerar las condiciones ambientales, culturales y sociales como factores que pueden afectar la autonomía y la participación de una persona con discapacidad en la sociedad: discapacidad entendida desde las interacciones del individuo con el entorno. Por ejemplo, la discapacidad de una persona usuaria de silla de ruedas proviene, no del hecho de no poder caminar, sino de los obstáculos a los que se enfrenta a diario para poder acceder a distintos lugares.

- La ley estipula que el men debe aplicar una política de educación inclusiva según lo dispuesto en la CDPD, en cumplimiento de lo cual debe: i) incentivar a las instituciones de educación superior a invertir recursos en investigación, programas y estrategias de desarrollo de tecnologías inclusivas y derecho universal; ii) asegurar que

31 Para el análisis se tuvieron en cuenta: Ley 30 de 1992, Ley 115 de 1994, Ley 324 de 1996, Ley 361 de 1997, Ley 762 de 2002, Ley 982 de 2005, Ley 1145 de 2007, Ley 1346 de 2009, Ley 1618 de 2013, Decreto 907 de 1996, Decreto 2082 de 1996, Decreto 2369 de 1997, Decreto 3011 de 1997, Decreto 366 de 2009 y Resolución 2565 de 2003. todos los exámenes estatales que midan el nivel académico de los estudiantes sean accesibles y adecuados para las personas con discapacidad y iii) garantizar la admisión, permanencia y promoción en los sistemas de educación superior de las personas con discapacidad.

- Se determinan los criterios que se deben seguir para integrar en el sistema educativo a las personas con discapacidad: medidas de apoyo, promoción de aulas especializadas, ajuste de los programas educativos, programas de reincorporación y capacitación debida de docentes. Las instituciones de educación superior deben, progresivamente, crear las medidas necesarias para brindar el apoyo técnico que necesiten las personas sordas para tener las mismas condiciones y oportunidades de los demás estudiantes. Con el Decreto 366 de 2009 se organiza la prestación del servicio de educación y se empiezan a diferenciar las estrategias según el tipo de discapacidad, lo cual es un factor esencial para entender la discapacidad como una manifestación de la diversidad humana, que los apoyos cambian según las características de cada persona, y no como un bloque homogéneo como se venía haciendo.

- Se estructura un sistema exclusivo que aboga por los derechos de las personas con discapacidad: el Sistema Nacional de Discapacidad (SND), que se encarga de la coordinación de todos los actores que tienen que ver con la integración social de la población con discapacidad, con el fin de que se organice la oferta de programas y servicios, así como promover su participación en la creación de políticas públicas que equiparen 
sus oportunidades. Asimismo, se crea el Consejo Nacional de Discapacidad (CND), que se encarga de coordinar, planificar, concertar, adoptar y evaluar las políticas públicas generales y sectoriales de la discapacidad en el país. Tanto el SND como el CND deben contar con representantes de la comunidad con discapacidad, lo que significa un avance en cuanto a su integración en la formulación y vigilancia de políticas. De la misma manera, con el Decreto 2082 de 1996 se crean las aulas de apoyo especializadas "como un conjunto de servicios, estrategias y recursos que ofrecen los establecimientos educativos para brindar los soportes que permitan la atención integral de los estudiantes con limitaciones o con capacidades o talentos excepcionales" y la ual (unidad de atención integral) "como un conjunto de programas y servicios profesionales interdisciplinarios que las entidades territoriales ofrecen a los establecimientos educativos que integran en sus aulas estudiantes con necesidades educativas especiales".

- La ley se preocupa por aclarar y definir términos importantes respecto de la comunidad con discapacidad auditiva, entre ellos: hipoacusia, sordo, limitación auditiva, comunicación, intérprete, lengua de señas, sordo señante, sordo hablante, sordo monolingüe, sordo bilingüe y sordo semilingüe. La conceptualización permite aclarar ideas preconcebidas que la comunidad oyente tiene con frecuencia respecto de la comunidad sorda y conocer con mayor precisión la dimensión integral de la discapacidad auditiva.

- Se avanza en la inclusión de la lengua de señas en programas informativos nacionales y de interés cultural, político, educativo y social, además de destinar recursos económicos para lograr que se incluya en los canales locales, regionales y nacionales. Se destaca la obligación estatal de promover intérpretes idóneos para el acceso de las personas sordas a los servicios públicos (como la educación superior), además de promover la creación de escuelas de formación de intérpretes.

- Un avance nuevo y muy importante de la legislación referente a la educación, es que le empieza a otorgar un valor superior al educando como centro del proceso educativo, lo que implica que debe participar activamente en su formación integral y en el desarrollo de su educación. Ser el centro del proceso quiere decir que todas las medidas deben estar encaminadas a cumplir las necesidades colectivas e individuales de los estudiantes, lo que permite hablar de los apoyos que requieren las personas sordas y con discapacidad auditiva.

- Tras una lucha histórica, la Lsc es considerada un medio válido de expresión de voluntad. Así, el Estado deberá apoyar las actividades de investigación, educación y difusión de la LSC y la creación de escuelas de formación de intérpretes para Sordos. Igualmente, deberá proveer intérpretes idóneos para que las personas sordas puedan acceder a todos los servicios que la Constitución les confiere (entre ellos la educación). El Decreto 2369 de 1997 añade el concepto de educación bilingüe en su artículo 14. Según Hurtado (2004) "la intención de esta nueva reglamentación era buscar la igualdad de participación (en la vida social, política, econó- 
mica, cultural, científica y productiva), la autonomía lingüística y el desarrollo integral del Sordo, en contraste con la legislación anterior".

- Otro avance importante es respecto a la noción de barreras. Es posible ver cómo en las primeras leyes sobre discapacidad únicamente se tenían en cuenta las barreras arquitectónicas -se hablaba de rampas, puertas de acceso, señalizaciones-, y con el tiempo se fue evolucionando para tener en cuenta otras como las actitudinales y las comunicacionales.

- La noción de "rehabilitación" que contemplaba la legislación inicial sobre discapacidad también sufrió un importante cambio: se empieza a hablar de rehabilitación integral, que comprende el mejoramiento de la calidad de vida de las personas sordas y la plena integración de la comunidad con discapacidad al medio familiar, social y ocupacional.

Reconocidos los avances es importante identificar varias debilidades en los instrumentos analizados:

- La Ley 30 de 1992, que regula específicamente la educación superior, no contiene ningún artículo que haga referencia a las personas con discapacidad y mucho menos a las personas sordas. Es muy clara en cuanto a los objetivos específicos de todas las instituciones que hacen parte de la educación superior, pero muy vaga al hablar de cómo se pueden lograr dichos objetivos, sobre todo cuando se trata de estudiantes que requieren una atención y apoyo adicional como las personas sordas. Sin embargo, en el
2009 aparece el Decreto 366 que reglamenta la organización del servicio de apoyo pedagógico para la atención de los estudiantes con discapacidad y con capacidades o con talentos excepcionales, en el marco de la educación inclusiva. En él por primera vez se define estudiante con discapacidad, pero desde la idea de "lo que no pueden hacer" y no desde sus habilidades y capacidades.

- La Ley 324 de 1996, desde el momento de su promulgación, se convirtió en una bandera de triunfo pues fue el resultado del trabajo conjunto entre Fenascol, el Insor y la comunidad sorda. La principal conquista estaba en el artículo 2 que señalaba: “El Estado Colombiano reconoce la Lengua Manual Colombiana, como idioma propio de la Comunidad Sorda del país". Según Fenascol (1996), con esta ley Colombia se había convertido en el primer país en América y cuarto en el mundo, donde el Gobierno reconocía legalmente una lengua de señas. El logro era evidente, sin embargo el 26 de febrero de 2002 la ley fue demandada, y la Corte Constitucional decidió declarar inexequible el artículo 2. ${ }^{32}$

La inexequibilidad del artículo 2 es un paso atrás en el reconocimiento de la comunidad sorda como minoría lingüística, y aunque la ley fue sin duda un gran avance para la comunidad, afecta directamente las disposiciones educativas que en ella se contienen, pues después de la decisión de la Corte la Lsc no se tiene en cuenta dentro de los procesos educativos, debilitando la enseñanza bilingüe de las personas

32 La sentencia C-128 de 2002 se analiza en el acápite de jurisprudencia. 
sordas. Sin embargo, la legislación vigente considera la Lsc como una lengua necesaria para la comunicación de las personas con algún tipo de discapacidad auditiva, es reconocida por el Estado como esencial para el desarrollo del pensamiento de las personas sordas y se promueve su aprendizaje, de hecho, la ley propone explícitamente que las personas sordas sean bilingües.

- La totalidad de las leyes analizadas continúan utilizando un lenguaje Ileno de connotaciones negativas sobre la discapacidad. Algunos ejemplos son: “limitación”, “limitado”, “disminución”, "disminuido", "adolecer de discapacidad" y "deficiencia". Aunque estas palabras se encuentran presentes en el cuerpo de las leyes, también hacen parte de las definiciones de discapacidad que se desarrollan en ellas. En leyes recientes se dictaminó que la definición de discapacidad se podría modificar según las estipulaciones de la oms, lo que abre la posibilidad de cambiarla con el tiempo.

- La vigilancia sobre las cuestiones generales de discapacidad proviene principalmente del Ministerio de Salud. Asimismo, la ley se refiere constantemente a la necesidad de eliminar el origen de las "limitaciones" a través de intervenciones oportunas bajo un modelo de prevención, con el fin de que las personas con discapacidad "puedan modificar o normalizar sus vidas". La rehabilitación es vista como la manera para "restablecer" y "compensar" las "pérdidas" o "faltas" de alguna función. Sin duda, lo anterior demuestra una vez más que el país continúa abordando la discapacidad según un modelo médico de reha- bilitación, que busca "normalizar" y "readaptar" funcionalmente, para mejorar la calidad de vida de las personas con discapacidad. Estos conceptos están ligados estrechamente con el modelo de rehabilitación que se trató al inicio del trabajo, pues se medicaliza la discapacidad y se asocia a ella la idea de normalizar a las personas que tienen "deterioros físicos", en palabras de la ley. Nos seguimos enfrentando a definiciones que hablan de la discapacidad en términos de déficit, limitación y pérdida, dándole un carácter negativo que continúa estigmatizando a las personas con discapacidad. Uno de los objetivos de la ley es lograr que las personas sordas “estén en condiciones de alcanzar y mantener un estado funcional óptimo", como si este no se pudiera alcanzar por el simple hecho de tener una discapacidad.

- La legislación no adopta realmente el concepto de inclusión y, en cambio, utiliza la noción de integración, que es muy diferente. La integración se refiere simplemente al hecho de hacer que una persona o un grupo de personas se incorpore a otro grupo, lo que podríamos entender como una inserción parcial que no genera cambios profundos ni estructurados. Integrar un grupo a otro significa que los miembros del primero se deben adaptar al modelo que ya existe en el segundo, además de considerar a sus miembros como un bloque homogéneo. El concepto de inclusión es distinto. Incluir a un grupo implica que la sociedad receptora se adapte para atender las necesidades de los miembros de este, entendidos como sujetos individuales de derechos. De esta manera, la incorporación logra ser total y genera cambios profundos y a 
largo plazo en la sociedad. Aunque en la ley aparece el término "inclusión" en materia de educación, el contenido de esta sigue siendo de integración, pues no se garantizan las necesidades particulares de cada estudiante.

- La legislación continúa hablando de programas educativos "especiales" o de "atención especial”. Según el Diccionario de la Lengua Española, especial significa "[q]ue es raro, poco corriente o diferente de lo ordinario". Calificar algo como especial implica que hay algo que consideramos normal, y que por tanto lo especial es diferente. Si queremos avanzar hacia la inclusión educativa, la ley no puede seguir considerando a las personas sordas como diferentes y desiguales respecto a la comunidad oyente.

- La promoción de la cooperación para generar políticas públicas a través de organizaciones de personas con discapacidad se queda todavía muy corta. En varias ocasiones, pareciera que la ley fue escrita sin tener en cuenta las necesidades propias y específicas de la comunidad sorda, pues se habla de derechos humanos en abstracto y no se identifican cuidadosamente las políticas que se deben seguir para cada tipo de discapacidad. Los apoyos requeridos por una persona Sorda no son los mismos que necesita alguien con una discapacidad psicosocial, por ejemplo. Aunque la ley hace un intento por diferenciar las políticas públicas entre tipos de discapacidad, todavía falta mucho en cuanto a no seguir considerando a las personas con discapacidad como un bloque homogéneo, y más bien especificar las políticas de acuerdo con sus necesidades explícitas.
- Existe un problema sobre cómo están estructuradas las leyes en el sistema educativo para las personas con discapacidad, pues el modelo está montado sobre la idea de capacidades humanas (Parra, 2014), concretamente en méritos, es decir, con base en las capacidades o talentos excepcionales de las personas, no en la diversidad humana. El tema debe ser estudiado desde la óptica de la diversidad y de la riqueza humana, y no necesariamente desde las capacidades, porque ¿qué pasa si no tengo una capacidad sobresaliente?

\section{Jurisprudencia de la Corte Constitucional de Colombia}

Para el presente análisis jurisprudencial se tuvieron en cuenta varias sentencias de la Corte Constitucional, ${ }^{33}$ referentes al derecho a la educación y al acceso y permanencia en la educación superior de personas con discapacidad. A continuación se mostrarán las fortalezas que a mi parecer deben ser resaltadas:

- Es notable cómo la Corte Constitucional en su desarrollo jurisprudencial le ha venido dando un lugar trascendental al derecho a la educación al considerarlo como inherente a las personas, como un derecho fundamental y como un servicio público que tiene una función social según lo estipulado en la Constitución Política. Por estas razones, nadie puede ser discriminado para acceder y permanecer en el sistema educativo,

33 Especificamente las sentencias: T-429 de 1992, T-002 de 1992, T-036 de 1993, T-329 de 1997, T-513 de 1999, T-620 de 1999, C-128 de 2002, T-397 de 2004, T-826 de 2004, T-170 de 2007, T-487 de 2007, T-051 de 2011 y T-694 de 2011. 
independientemente de que sea una entidad pública o privada. Asimismo, la Corte reconoce que no solo a través de la Constitución se protege este derecho, sino que los instrumentos internacionales -a través del bloque de constitucionalidad-también reconocen que el derecho a la educación de las personas con discapacidad es fundamental, de aplicación inmediata y requisito sine qua non para garantizar la protección y garantía de los demás derechos.

- La obligación de garantizar el derecho a la educación de las personas con discapacidad es del Estado, mediante medidas específicas que aseguren su goce efectivo y teniendo en cuenta la situación de cada estudiante. El Estado será el encargado de promover políticas de educación inclusiva que equiparen las oportunidades de personas con y sin discapacidad.

- La jurisprudencia de la Corte Constitucional afirma que las cifras demuestran que no se está garantizando el acceso ni la permanencia en la educación superior de las personas con discapacidad, debido a que no hay una política pública eficiente que garantice la inclusión de esta población. Sumado a esto, la sociedad todavía presenta falsos imaginarios sobre las capacidades y habilidades de las personas con discapacidad, especialmente en el ámbito educativo, además de sentimientos de vergüenza, lástima e incomodidad, que impiden lograr una debida inclusión. Por estas razones, la jurisprudencia reconoce que la política pública que intente proteger este derecho deberá tener en cuenta dos factores esenciales: el respeto por la diversidad y la importancia de una comunidad académica incluyente.
- En reiteradas sentencias la Corte asegura que a través del derecho a la educación se garantizan otros derechos fundamentales como la igualdad y el trabajo. El derecho a la igualdad obliga al Estado a adelantar acciones afirmativas a favor de los grupos que han sido históricamente vulnerados y excluidos de la sociedad, como es el caso de las personas en situación de discapacidad. Asimismo, la Corte muestra tres maneras de violar el derecho a la igualdad: i) desde las normas, ii) desde las prácticas de las instituciones y, iii) desde la sociedad, lo que lleva a que la población con discapacidad tenga que soportar cargas extras que desde cualquier punto de vista son injustificables.

- La Corte es muy clara al referirse a la protección especial de que gozan las personas con discapacidad en nuestro país. Según lo estipulado en la sentencia T-397 de 2004, existen tres postulados básicos que deben ser tenidos en cuenta: (a) la igualdad de derechos y oportunidades entre las personas con discapacidad y los demás miembros de la sociedad, con la consiguiente prohibición de cualquier discriminación por motivos de discapacidad; (b) el derecho de las personas con discapacidad a que se adopten todas las medidas necesarias para poder ejercer sus derechos fundamentales en pie de igualdad con los demás; y (c) el deber estatal correlativo de otorgar un trato especial a las personas con discapacidad.

- A través de la jurisprudencia, la Corte ha hecho énfasis en la protección reforzada que tiene el Estado sobre las personas con discapacidad, especialmente por lo que estipula el artículo 13 
de la Constitución respecto a las personas que se encuentran en debilidad manifiesta. Todo lo anterior, a través de acciones afirmativas y de igualdad promocional, para garantizar que el acceso y la permanencia en el sistema educativo se dé en igualdad de condiciones.

- La jurisprudencia deja claro que el núcleo esencial del derecho a la educación comprende el acceso y la permanencia en el sistema educativo. La sentencia T-329 de 1997 afirma que el derecho al acceso es un presupuesto para que se cumpla el derecho a la educación, el cual se materializa en el acto de matrícula. Es importante referirnos a la aclaración que la jurisprudencia hace respecto de las instituciones educativas privadas y públicas, pues ninguna de ellas puede estorbar ni el acceso ni la permanencia de los estudiantes "mediante actos, acuerdos, medidas, prácticas cuyo efecto real, querido o no, sea la negación del derecho a la educación en todas sus manifestaciones" (sentencia, T-429 de 1992). Finalmente, la Corte considera que son las entidades estatales las encargadas de la disponibilidad, el acceso, la permanencia y la calidad en la prestación del servicio de educación, lo cual se debe suministrar en condiciones de igualdad y bajo las circunstancias particulares de las personas con discapacidad.

- El segundo elemento que hace parte del derecho a la educación es la permanencia en el sistema educativo, la cual implica, según la Corte, realizar acciones concretas que permitan responder a las necesidades educativas de todos los estudiantes y eliminar las barreras que puedan impedir la finalización de los estudios.
Siempre existen alternativas pedagógicas válidas para asegurar la permanencia de los estudiantes con discapacidad en el sistema de educación superior.

- La idea de educación inclusiva para personas con discapacidad no solo se da desde la óptica de la Constitución Política que la concibe como derecho fundamental, sino bajo todos los instrumentos internacionales que integran el bloque de constitucionalidad. Las cifras sobre el índice de accesibilidad y permanencia de las personas en situación de discapacidad muestran que solo el 1\% de esta población logra finalizar sus estudios de educación superior; el porcentaje de personas que continúan con sus estudios de posgrado es obviamente más bajo, evidenciando problemas en las políticas públicas de educación inclusiva de la población con discapacidad. Por estas razones, la jurisprudencia asegura que es menester empezar a crear e implementar las normas que desarrollan este contenido, hace un llamado sobre la urgencia de crear dichas políticas y asegura que estas se deben construir bajo dos presupuestos importantes: (i) el respeto por la diversidad y (ii) la importancia de una comunidad académica incluyente.

- La educación inclusiva debe ser también vista como un aporte a la diversidad. Es esencial que los niños con y sin discapacidad compartan e interactúen en los mismos espacios para promover la aceptación y el respeto de ambas partes, teniendo en cuenta que uno de los fines de la educación, según la Ley 115 de 1994, es la “formación en el respeto a la vida y a los demás 
derechos humanos, a la paz, a los principios democráticos, de convivencia, pluralismo, justicia, solidaridad y equidad, así como en el ejercicio de la tolerancia y de la libertad".

- La jurisprudencia empieza a incluir en sus decisiones y consideraciones la opinión de las personas con discapacidad. La sentencia C-128 de 2002 que discute el reconocimiento de la LSC como idioma propio de la comunidad Sorda, la tuvo en cuenta en la decisión a través de varios testimonios de personas Sordas, padres de niños y niñas Sordos e integrantes de instituciones como Fenascol e Insor, lo que demuestra un interés por identificar las verdaderas problemáticas y por conocer de una manera más cercana la situación real de las personas Sordas.

- Relacionado con el tema de educación inclusiva, la jurisprudencia desarrolla el principio de autonomía universitaria consagrado en el artículo 69 de la Constitución. A pesar de aceptar que este principio fortalece la democracia al permitir que la educación sea un derecho y un servicio público, con una función social que se realiza en un espacio caracterizado por la libertad de pensamiento, libertad de cátedra, ambiente de independencia, entre otras (sentencia T-551 de 2011), la Corte ha sostenido que la facultad que tienen las instituciones universitarias - públicas y privadas- de actuar con plena independencia no es absoluta, pues encuentra el límite en lo que establece la Constitución Política y la ley, esencialmente respecto de los derechos fundamentales (tales como el derecho a la educación).
En resumen, las actuaciones de las instituciones universitarias deben estar en concordancia con los principios y valores constitucionales, pero, sobre todo, con los derechos fundamentales de los estudiantes. De lo anterior se desprende que las actuaciones de las instituciones que puedan afectar el núcleo esencial del derecho a la educación deben ser consideradas inconstitucionales, como es, para nuestro objeto de estudio, impedir el acceso o la permanencia en la educación superior de las personas con discapacidad.

- La jurisprudencia desarrolla la idea de acciones afirmativas frente a las personas en situación de discapacidad, contenidas en el artículo 13 de la Constitución. Con estas medidas, el Estado busca equilibrar los efectos negativos que la discapacidad genera en la participación de esta población. Respecto a la educación superior, la Corte señala la necesidad urgente de intervención del Estado para desarrollar las medidas afirmativas necesarias que logren igualdad real de condiciones en cuanto al acceso y la permanencia frente al resto de la población estudiantil.

Los avances que se han logrado con la jurisprudencia de la Corte Constitucional son evidentes y muy significativos en lo que se refiere al derecho a la educación de las personas con discapacidad. Sin embargo, las debilidades en su línea jurisprudencial también deben ser identificadas:

- En varios casos de estudiantes con discapacidad, la Corte afirma la necesidad de evaluar su “nivel de funcionamiento", para de esta mane- 
ra determinar su grado de "integrabilidad", con lo cual indica que algunos estudiantes podrán ser integrados y otros no, y que estos últimos deberán entrar a un programa de habilitación o rehabilitación. Debo decir que la educación superior, a diferencia de la educación básica y media, sí tiene un filtro en cuanto al nivel de conocimiento esperado y requerido. Sin embargo, si el estudiante con o sin discapacidad cumple con dicho requisito, no hay necesidad alguna de "evaluar su nivel de funcionamiento" y de esta forma determinar si se puede o no integrar al sistema educativo. Si existen los ajustes razonables para que el estudiante con discapacidad cumpla con el requisito exigido para acceder a la educación superior, no debe haber una carga extra que además de etiquetarlo y categorizarlo infundadamente, no cumpla con la obligación de garantizar la igualdad de oportunidades.

- La jurisprudencia mantiene el lenguaje discriminador y negativo frente a la discapacidad del que he hablado en varias ocasiones. Incluso, sentencias recientes utilizan términos como: "sujetos especiales", "persona discapacitada", “deficiencias", "personas normales", “límites", "impedimentos", "limitados auditivos" y "personas diferentes". También es posible apreciar, cómo en jurisprudencia de años recientes se empiezan a usar comillas cuando se usan este tipo de términos, práctica que también crea estereotipos negativos sobre la supuesta deficiencia de las personas con discapacidad.

- En algunas sentencias la Corte asemeja las personas con discapacidad con menores de edad: "Si bien estos dos pacientes son ya perso- nas mayores de edad, la grave discapacidad que los aqueja los hace asimilables a los menores de edad. En realidad, aun cuando la edad biológica de estas dos personas los hace mayores, de acuerdo con los médicos tratantes, su edad mental corresponde a la de un niño menor" (sentencia T-487 de 2007). La infantilización de la discapacidad es un problema muy grave que debe ser erradicado del discurso sobre los derechos de las personas con discapacidad. Esta visión está impregnada de rezagos de los modelos de prescindencia y rehabilitación que ya he explicado, pues contiene sentimientos de lástima y de pesar que sostienen la idea errada de inferioridad.

- En varias discusiones sobre derechos de personas sordas, como por ejemplo en el debate sobre si reconocer o no a la Lsc como lengua válida en el ordenamiento colombiano, se pide en primer lugar la intervención del Ministerio de Salud. Que a través de la salud se vigile y se normativicen todos los temas relacionados con discapacidad solo demuestra que el país continúa con remisiones importantes al modelo rehabilitador o médico, que define la discapacidad desde las "deficiencias" del individuo y no desde las deficiencias del entorno que lo excluye.

- Como dije anteriormente, la sentencia C-128 de 2002 mediante la cual se declaró inexequible el artículo 2 de la Ley 324 de 1996 que estipulaba: “El Estado Colombiano reconoce la Lengua Manual Colombiana, como idioma propio de la Comunidad Sorda del País", es un gran retroceso. Martha Lucía Osorno, líder sorda de Fenascol asegura que: 
Hoy en día, viendo el evidente fracaso educativo con respecto a los sordos en la oralización, se quiere implementar una educación bilingüe real, no superficial. Es lo mismo que se da en el caso de la etnoeducación para los indígenas: para la preservación de la cultura y los valores lingüísticos, se necesitan maestros capacitados en las dos lenguas y el reconocimiento de la lengua como parte integrante de la cultura (citada en Hurtado, 2004).

Reconocer la Lsc como el idioma propio de la comunidad sorda era un paso más hacia la identificación de una comunidad cultural fuerte con características propias, y una manera de influir directamente en el ámbito educativo puesto que se ponía de manifiesto la necesidad de incluir la Lsc en todas las actividades académicas que tuvieran que ver con personas sordas. Sin embargo, el artículo se prestaba para malos entendidos, puesto que se concebía la Lsc como única forma de comunicación de las personas sordas, y por tanto como única lengua para educar. En esto se basó la declaratoria de inconstitucionalidad, por considerar que no estaba abierta a la alternativa de la escuela oralista, que muchas personas y familias sordas aprueban como método idóneo para su formación como personas y estudiantes. La ley además evidencia la tensión que todavía existe entre escuelas de educación para personas sordas, y el rechazo de una parte de la comunidad sorda a considerarse minoría lingüística. Sin duda, la ley debe ser redactada de una manera incluyente, esto es, que integre las diferentes alternativas que la persona sorda tiene y no restrinja la posibilidad de comunicación a través de vías distintas a la Lsc.
El concepto de "educación especial" varía a medida que se desarrolla la jurisprudencia. En sentencias recientes, la Corte señala que la educación especial debe ser reemplazada por el concepto de educación inclusiva, un paso más cerca hacia la igualdad de oportunidades de personas con y sin discapacidad. Lo anterior debido a que la Corte pone en duda la idea de que con la educación especial se promuevan las condiciones para que la igualdad sea real y efectiva, y más bien a través de ella se favorece la discriminación y la marginación de quienes la reciben: "un campo propicio para colocar a sus usuarios "en el centro mismo del paradigma normal - anormal”, con la alta carga de discriminación implícita o explícita que ello acarrea" (sentencia T-513 de 1999).

Sin embargo, jurisprudencia reciente ha señalado que la educación especial sí se puede concebir, aunque solo como un recurso extremo, cuando se concluya que es la única posibilidad de hacer efectivo el derecho a la educación de una persona con discapacidad. Lo anterior se evalúa a través de una "demostración profesional de su necesidad", en palabras de la Corte. No es claro si esta demostración la tiene que hacer un profesor, un médico o qué tipo de profesional, tampoco se aclara cómo se debe hacer. En este punto se refuerza la costumbre errada de etiquetar y graduar a las personas con discapacidad, en vez de modificar las formas de enseñanza tradicionales existentes para adecuarlas a cada una de las necesidades de los estudiantes con discapacidad, bajo un modelo de la diversidad que tenga en cuenta las particularidades de cada quien. 


\section{APUNTES FINALES}

Después del anterior análisis del marco regulatorio nacional e internacional en cuanto al acceso y a la permanencia en la educación superior de las personas sordas, propongo una serie de conclusiones que me permitirán responder a la pregunta de investigación, comprobar o negar la hipótesis, determinar los obstáculos que existen y especificar los ajustes razonables necesarios para garantizar a cabalidad este derecho.

\section{Promoción y reconocimiento de la identidad sorda}

La promoción y el reconocimiento de una identidad sorda por parte del Estado son esenciales para la construcción y el fortalecimiento de la comunidad sorda como tal. Hemos visto que la Lsc es uno de los elementos más importantes para lograr la reivindicación total de las personas sordas en la comunidad, además de tener serias implicaciones para la educación. La promoción del fortalecimiento de esta identidad es necesaria, pues desde el modelo de oyentes las personas sordas tienen muchas posibilidades de fracasar en el sistema educativo, aún más cuando no se cuenta con los recursos económicos para realizar los ajustes necesarios. Aunque el presente trabajo considera que la educación de las personas sordas debe ser a través de la Lsc y no comparte los postulados de la escuela oralista, también cree que el Estado debe, de todas formas, garantizar el derecho que tienen las familias de niños y niñas Sordos a escoger la forma de comunicación que consideren más adecuada para su desarrollo.
De igual manera, la ssc no debe ser considerada incompatible con la forma de comunicación mayoritaria, pero sí ser respetada y protegida. Se debe promover el bilingüismo de las dos comunidades: oyente y sorda, de forma que les sea más fácil su interacción y el acceso a la educación superior, pues hemos visto cómo el déficit en castellano de la comunidad sorda afecta directamente su acceso al conocimiento y su posibilidad de permanecer en el sistema educativo.

Asimismo, la promoción que realice el Estado debe ir de la mano con una investigación integral y continua -antropológica y sociológica- de la comunidad sorda, con el fin de conocer sus características propias y hallar información que facilite la comprensión de los aspectos sociales que hacen parte de ella, lo que va a permitir diseñar las medidas más apropiadas para el restablecimiento de sus derechos. Es evidente que la falta de conocimiento sobre la historia, la lengua y la identidad de la comunidad sorda, además del desconocimiento en cuanto a los avances que se han logrado en términos jurídicos, hace más proclives a los integrantes de esta comunidad a no identificarse como miembros de una minoría, y a desconocer sus derechos fundamentales especialmente en espacios educativos.

En nuestro país y jurídicamente hablando, con la Ley 1618 de 2013 y con la CDPD se lograron grandes avances en materia de derechos para las personas con discapacidad, sin embargo, estos instrumentos no reconocen explícitamente a la comunidad sorda, y menos como una comunidad lingüística. Por estas razones, actualmente el estudio de la comunidad se hace 
todavía desde un enfoque de personas con discapacidad que, por su condición, reciben una especial protección por parte del Estado. El camino para considerarse comunidad lingüística es muy largo y requiere de un estudio juicioso de los elementos necesarios para que se configure de esta manera.

\section{Fortalecimiento de las políticas sobre educación superior para personas con discapacidad}

Según Garzón Gil (2014) las políticas públicas referentes a la educación básica y media de personas con discapacidad son muy fuertes y al parecer están teniendo buenos resultados. Efecto de ello puede ser el que cada vez más personas con discapacidad aspiran ingresar a la universidad. Si la educación superior no está preparada para atender la población que llega el avance que se ha logrado se frena, pues como se ha dicho anteriormente, el acceso a la educación superior es difícil para las personas con discapacidad. Hemos visto que no existe una política pública específica de educación superior para personas con discapacidad, en la que se den lineamientos claros para el acceso y la permanencia. Aunque existen instrumentos como el Conpes 166 de 2013, que intenta rediseñar la política pública de discapacidad hasta el momento establecida, las directrices específicas sobre educación superior que se plasman con respecto al acceso y la permanencia son, a mi parecer, vagas e insuficientes.

Colombia ha realizado un importante avance en materia legislativa sobre este tema, sin em- bargo, si no hay una política específica es muy difícil promover la reivindicación del derecho a la educación de las personas sordas. Asimismo, es imposible lograr lo anterior si las universidades no han creado todavía servicios de apoyo y atención permanente para los estudiantes que presenten algún tipo de discapacidad, y que además los incluyan en las propuestas y proyectos que se están realizando para mejorar las condiciones de esta población. En palabras de Collazos (2014) "el sistema educativo en su conjunto no está preparado, la educación privada y las universidades privadas si bien se acogen a unos lineamientos y elementos de la educación, tienen la posibilidad de ser selectivas y de excluir a la gente". Por estas razones, Ios lineamientos que se expidan deben estar encaminados a resolver las dificultades de acceso y los obstáculos que inciden en el alto índice de deserción estudiantil.

\section{El concepto de discapacidad tiene todavía rezagos del modelo médico}

Después de ver el enfoque de normalización de varias leyes y políticas de nuestro país, es evidente que Colombia se ubica todavía en el modelo médico de discapacidad, y así es difícil que las políticas de educación sean inclusivas. Además de evidenciar en el trabajo de investigación los problemas que presenta el lenguaje en la mayoría de instrumentos jurídicos, vemos que la vigilancia, las cifras y los direccionamientos provienen del Ministerio de Salud. Las cifras que presentó el DANE gracias al censo de $2005-$ con las que se fundamentó este trabajo-fueron trasladadas al Ministerio de Salud a principios 
de este año. Asimismo, existe un constante esfuerzo por diagnosticar y graduar la discapacidad, como si eso pudiera afectar o modificar la obligación estatal de garantizar el derecho a la educación superior.

La óptica clínica de la discapacidad define a las personas por lo que no pueden hacer, y no por sus habilidades y capacidades; es necesario que el país entienda la discapacidad como una manifestación de la diversidad humana, y no como el resultado de una valoración médica. Lo anterior refuerza la concepción de la comunidad oyente sobre la sordera como una enfermedad y una limitación, imaginarios que traducidos en estereotipos solo logran reforzar la discriminación de esta comunidad en varios ámbitos, uno de ellos el educativo. También es importante hacer alusión a la gravedad de que no existan cifras confiables, puesto que muchas están desactualizadas, otras no están discriminadas por tipos de discapacidad auditiva y otras simplemente están mal calculadas.

\section{Diálogo entre las dos comunidades}

El diálogo entre la comunidad sorda y la oyente es vital para generar una comunicación desde la igualdad, que permita un cambio de mentalidad sobre la discapacidad, la eliminación de estereotipos infundados y la creación de propuestas de solución adecuadas a las necesidades reales de las dos comunidades. Pueden existir muchos mecanismos que permiten el acceso y la permanencia en la educación superior de las personas sordas, pero de nada sirven frente a la resistencia a contratarlas y a incluirlas en la fuerza labo- ral. A su vez, es necesario un empoderamiento fuerte de la sociedad civil sorda a través de procesos orientados a fortalecer sus comunidades, a incidir en política, a exigir la garantía de sus derechos y al trabajo en conjunto en la creación de políticas públicas. Colombia es una sociedad todavía muy excluyente, y la inclusión implica transformaciones en todos los niveles de la educación, pero además transformaciones sociales y culturales muy fuertes en las que la comunidad sorda debe ser la primera en manifestarse. Saber qué quieren las personas sordas específicamente respecto a la educación superior facilitará el diseño de políticas públicas adecuadas.

Es importante comprender que la comunidad oyente puede aprender la Lsc, pero la comunidad sorda no puede aprender a oír. La invitación es a que las personas oyentes aprendan la Lsc y se integren a la comunidad sorda. En palabras de Edna Garzón ${ }^{34}$ (2014):

todas las personas oyentes que se interesan en aprender, por supuesto nosotras, las personas sordas, estamos dispuestas con mucho gusto a apoyarles para que aprendan (...) hay personas comprometidas con las que cada vez que podemos compartimos, ellas se integran a nuestra comunidad y nosotros les enseñamos poco a poco las señas. Así como cuando alguien está aprendiendo hablar, nosotros podemos repetir las señas, para que las personas oyentes puedan entrar en ese interés por nosotras las personas sordas.

34 Persona sorda bachiller del colegio Filadelfia. Edna ingresó a la Universidad del Rosario a estudiar psicología, y por diferentes motivos tuvo que desertar en tercer semestre. Actualmente es estudiante de sexto semestre en la Universidad Pedagógica de Colombia. Edna es nadadora profesional. 


\section{Propuestas específicas de inclusión dentro de las universidades}

A mi parecer, las políticas universitarias para personas sordas deben tener en cuenta los siguientes elementos:

- Programa de lectoescritura en español como segunda lengua. Uno de los aspectos que impide la permanencia de las personas sordas en la universidad es la gran deficiencia en lectura y escritura en español. Si el colegio no garantiza un nivel adecuado, la universidad puede tener programas y adoptar medidas para nivelar a los estudiantes Sordos.

- Programas que refuercen el bilingüismo no solo para la comunidad sorda. Deben existir cursos dentro del área de lenguaje tanto de LSc como de español para personas sordas, teniendo en cuenta que las lecturas, exposiciones y ayudas pedagógicas son en español.

- Aunque los avances en educación básica y media son importantes, el nivel académico de muchos bachilleres Sordos no es el mejor, y el acceso y permanencia en la educación superior les es imposible si no hay una debida nivelación. El "semestre cero" es una alternativa utilizada por varias instituciones para nivelar en diferentes áreas a quienes ingresan a la universidad con un nivel académico más bajo que el resto de estudiantes, con el fin de que puedan cursar con éxito los demás semestres. Esta práctica aplica también para las personas Sordas. La Universidad Pedagógica Nacional, por ejemplo, cuenta con esta estrategia de nivelación para fortalecer la lengua de señas y la lectoescritura del castellano, además de seminarios sobre orientación profesional y vocacional.

- La discriminación a las personas sordas, en su mayoría, obedece a ignorancia y falta de información. Las universidades pueden instituir una clase relacionada con los principios de inclusión social, donde se traten los elementos principales de la discapacidad y de otras formas de manifestación humana, construida conjuntamente con estas poblaciones.

- La capacitación y sensibilización a profesores $y$ al personal de servicios de la universidad es esencial. Asimismo, la realización de charlas a los estudiantes, dirigidas por alumnos con y sin discapacidad, que fomenten el reconocimiento de la diversidad y el respeto por el otro son vitales.

- El apoyo que se le brinde a una persona sorda no debe provenir solo del bienestar universitario. Para que sea integral debe comprometer todo el ambiente y al personal estudiantil para garantizar las mejores condiciones a los estudiantes con discapacidad. Según Garzón (2014), cada vez que un profesor nuevo llegaba a clase, ella debía contar nuevamente su situación y además explicarle cómo debía tratarla y cuáles eran los ajustes razonables que debía hacer.

- Las tutorías que se brindan a personas sordas deben estar encaminadas a reforzar sus conocimientos y a mitigar sus debilidades académicas. Muchas veces estas se limitan a ir a la biblioteca a leer sobre un tema o a investigar sobre una cuestión particular. 
- Mientras en las universidades no existan políticas de bilingüismo eficaces y que tengan en cuenta las necesidades particulares de la comunidad Sorda, los exámenes para esta población deberán someterse a ciertos ajustes. Se requiere de textos cortos para mayor entendimiento, $y$ algunos recomiendan la utilización de preguntas con opción de respuesta falso o verdadero o de conexión de conceptos. Los exámenes orales en Lsc son también una buena opción para personas Sordas, aunque hay que tener en cuenta que en ocasiones el vocabulario académico específico en la LSc está todavía en construcción. El punto aquí es la flexibilidad de los profesores sobre las formas de realizar sus exámenes, de la institución sobre el desarrollo curricular y de apertura mental hacia diversas formas de expresar el conocimiento.

- Los profesores pueden tener inquietudes y dudas sobre cómo tratar el tema. Ellos también requieren apoyo para solucionar estas cuestiones y para alcanzar un nivel aceptable de flexibilidad y adaptabilidad que les permita lograr mejores resultados.

- Las universidades deben estar en contacto y solicitar ayuda e información a la Red Colombiana de Instituciones de Educación Superior para la Discapacidad. Asimismo, pueden hacer parte de los debates que en ella se adelantan, participar en la construcción de acciones conjuntas, compartir experiencias y conocimientos que favorezcan la discusión académica.

\section{Las barreras actitudinales impiden la permanencia}

Hemos visto que existen muchas más barreras que las arquitectónicas. Una de estas es la actitudinal, cuya erradicación exige un verdadero cambio cultural, y es la de mayor incidencia en el hecho de que las personas sordas que ingresan a la educación continúen y se mantengan en ella.

Por un lado, algunos profesores se niegan a realizar exámenes más accesibles para las personas sordas, y quienes se muestran dispuestos hacen pequeñas adaptaciones que en la mayoría de los casos no son suficientes; por otra parte, la mayoría no saben cómo relacionarse con un estudiante Sordo ni con una comunidad distinta, desconocen la LSc y tienen actitudes despectivas frente a la posibilidad que estas personas puedan convertirse en profesionales; algunos utilizan frases como: "ay, pobrecita, es que ella es sorda, eso le va a afectar la vida", que evidencian la ignorancia en el tema y la concepción de la discapacidad como limitación y, por tanto, como motivo de lástima, visión que obviamente debe ser eliminada (Garzón, 2014); al mismo tiempo, olvidan que estas personas tienen problemas para realizar exposiciones, estudiar para parciales y hacer trabajos en grupo, "muchas veces no tienen en cuenta que hay una persona sorda en el grupo o simplemente no quieren interactuar conmigo" (Garzón, 2014). De aquí la importancia de reforzar la idea de inclusión, de diversidad y de eliminar barreras del entorno también en los estudiantes. 


\section{Intérpretes}

Este es uno de los aspectos que presenta más problemas en la práctica. Después de hablar con varias personas sordas y con algunos intérpretes pude identificar las siguientes dificultades:

- No hay una normatividad específica en el país que regule los intérpretes en cuanto a la calidad del servicio que deben proveer, las tarifas que pueden cobrar, los principios por los que se deben guiar, los requisitos mínimos que deben cumplir, las obligaciones de confidencialidad, etc.

- Hay mucha más demanda que oferta de personas intérpretes, lo que permite que los precios por hora de interpretación oscilen entre $\$ 40.000$ y $\$ 45.000$. Los altos costos impiden su contratación particular o institucional y repercuten en la permanencia de muchos estudiantes Sordos en la universidad.

- No todos los intérpretes tienen un nivel académico suficiente para apoyar a una persona sorda que cursa educación superior. La mayoría son bachilleres formados solamente en la LSC. Según Martínez (2014) “no es solo interpretar, no es suficiente, es aprender el arte de interpretar". Esto quiere decir que no cualquier persona puede interpretar, es necesario que se conozca y se interiorice la cultura sorda (Moyano, 2014). Muchas personas sordas concuerdan en que no hay confianza en los intérpretes, puesto que muchos no realizan las señas que son, no interpretan todo lo que se está diciendo o lo hacen de una forma incorrecta.
- Los intérpretes generalmente realizan interpretaciones por un lapso máximo de 45 minutos. En el cambio de intérprete, generalmente el estudiante Sordo pierde información importante de la clase.

- En la mayoría de casos no hay intérpretes fijos para un estudiante. Esto, sumado a que muchos llegan tarde y no tienen mayor compromiso con su trabajo, hace que los estudiantes Sordos estén en varios momentos de la clase sin interpretación alguna. “Una persona sorda necesita un intérprete que sea claro, que tenga compromiso, que sea cumplido, que los profesores de la universidad puedan hacer la adaptación con los intérpretes en el ámbito universitario, que la persona sorda se sienta bien con él" (Valencia, $2014)^{35}$.

- A diferencia de la educación básica y media, la educación superior exige que el intérprete, además de una formación académica avanzada, maneje el vocabulario específico de las materias, que no existe en la ssc y debe ir construyendo en la práctica. Este factor hace aún más difícil la comprensión de conceptos y contenidos de las clases por parte de las personas sordas.

- El trabajo de interpretación debe ir de la mano con el trabajo del docente de aula. No basta con traducir, también es importante saber si los conceptos han sido comprendidos completamente o si se necesita un refuerzo por parte del profesor.

35 Director de SURCOE - Asociación Colombiana de Sordociegos - y persona sordociega. 
- Según el mEN, actualmente en Colombia no hay intérpretes certificados. Para el Ministerio únicamente son intérpretes quienes poseen un título universitario, y este solo lo expide la Universidad del Valle, única institución que ofrece un programa en interpretación para sordos y sordociegos. El resto de personas que se consideran intérpretes no han tenido la formación necesaria para trabajar en el ámbito de la educación superior (Garzón, 2014). Sin duda, la falta de instituciones y establecimientos de formación es un problema que afecta directamente a la comunidad sorda.

- Los cursos de señas que existen actualmente no cumplen con los requisitos mínimos para que una persona pueda ser considerada intérprete. En opinión de la guía e intérprete Lucero Ballén ${ }^{36}$ (2004), es necesario que esta labor se profesionalice, y que los intérpretes tengan una formación integral en una carrera técnica de mínimo dos años.

- En los exámenes orales se presenta cierta desconfianza de los profesores hacia los intérpretes, por considerar que puede haber trampa entre ellos y los estudiantes Sordos. Asimismo, en varias ocasiones el intérprete no entiende las preguntas del docente y no sabe de qué forma explicársela al estudiante.

\section{Reestructuración de las pruebas estatales saber pro}

Las pruebas no cuentan con los ajustes razonables necesarios para garantizar que la po- blación Sorda pueda hacer el examen en las mismas condiciones que la población oyente. Siendo este un requisito para el acceso a la educación superior, debe ser reestructurado en los términos que propone la CDPD, la legislación y la jurisprudencia nacional.

\section{La diversidad de la comunidad Sorda}

Al igual que las personas oyentes, todas las personas Sordas son diferentes. Las políticas públicas de educación inclusiva deben respetar las características particulares de cada persona Sorda, de ahí la importancia del conocimiento de esta comunidad y de sus peculiaridades.

Igualmente, hay que tener en cuenta que el concepto de persona Sorda es muy amplio, y que una gran cantidad de actores juegan en él -algunas personas se reconocen como personas con discapacidad, otras no; unas como minoría lingüística, otras no-. Además de reconocer estas diferencias a la hora de diseñar políticas públicas, es importante tener en cuenta que muchos estudiantes Sordos pasan desapercibidos por el sistema de educación superior, porque mantienen un bajo perfil en la universidad, porque utilizan dispositivos auditivos o implantes y porque su idea es no ser reconocidos como Sordos, lo que influye en los datos que se tienen sobre esta comunidad y en la información sobre historias de éxitos o fracasos que se puedan presentar. 
10. Sí hay un marco regulatorio sobre la educación inclusiva de personas Sordas, sin embargo este es insuficiente

El concepto de inclusión educativa específicamente para personas con discapacidad está contenido en varias leyes, decretos, jurisprudencia y diferentes políticas públicas. Discursivamente hay un gran progreso, sin embargo, las cifras y los testimonios de la comunidad Sorda no demuestran dichos avances en la práctica.

Según Garzón Gil (2014) el 49\% de las personas Sordas que acceden a la educación terciaria desertan por diferentes razones, lo que quiere decir que los que quedan son buenos y tienen méritos para continuar. Es necesario tener en cuenta las adaptaciones que se requieren para apoyar la permanencia de estos estudiantes: menor velocidad del discurso del docente, disposición del aula en mesa redonda para que puedan ver al profesor, mayor tiempo para realizar las actividades, etc. Estos tipos de ajustes razonables no están regulados ni contemplados en ninguna ley o decreto. Lo ideal sería que con base en las políticas generales de educación inclusiva propuestas por el MEN, estos ajustes se realizaran de manera intuitiva, sin embargo creo que no estamos todavía en ese nivel y deben ser específicamente reglamentados para evitar más negaciones en el acceso y más deserciones. Los instrumentos jurídicos existen, pero en ellos no se encuentra el proceso que se debe seguir para que la ley funcione en la práctica.

Asimismo, la educación inclusiva debe ser resultado de un proceso de discusión continuo y dinámico entre docentes y estudiantes, como iguales, que no se enmarca en una única respuesta. Los últimos avances en materia de discapacidad son relevantes, y es apenas obvio que empiece a surgir la necesidad de crear lineamientos específicos para cada una de las poblaciones con discapacidad, producto de una investigación profunda, mesas de trabajo conjuntas, aportes de la academia, entre otros.

Finalmente, el Consejo Nacional de Acreditación que garantiza la calidad de las entidades de educación superior no tiene un componente de inclusión para personas con discapacidad. Hacer que un ítem para la acreditación de las universidades sea garantizar entornos accesibles y asequibles a todos evitaría varios pasos y permitiría garantizar el derecho a la educación más fácilmente. A pesar de todo, considero que hay grandes avances, y que aunque las políticas públicas en materia de educación inclusiva son todavía insuficientes, el ambiente es favorable para el cambio y el reconocimiento de la diversidad humana en el sistema de educación superior de Bogotá.

\section{Referencias}

Banco Mundial y Organización Mundial de la Salud. (2011). Informe mundial sobre la discapacidad. Ginebra: Ediciones de la oms.

Ballén, L. (21 de abril, 2014). Comunicación personal.

Becerra, R. (19 de marzo, 2014). Comunicación personal. 
Behares, L. (1997). Implicaciones teóricas (y de las otras) del descubrimiento de Stokoe. Ponencia presentada en el IV Congreso Latinoamericano de Educación Bilingüe para Sordos. Santafé de Bogotá, septiembre 30 a octubre 4.

Birdsong, D. (1999). Second Language Acquisition and the Critical Period Hypothesis. New Jersey: Lawrence Erlbaum Associates Publishers.

Buxó, M. J. (1983). Antropología lingüística. Cuadernos de Antropología, (3). Barcelona: Anthropos.

Castellanos, S. (2010). La lengua de señas desde el punto de vista lingüístico. En fENASCoL, Lengua de señas colombiana (t. I). Bogotá: Departamento de lingüística de la Universidad Nacional.

Cepeda, M. J. (1997). Los derechos fundamentales en la Constitución de 1991. (Segunda ed.). Bogotá: Editorial Temis.

Cocleares. (2012). Obtenido de Cochlear: http://www.cochlear.com/wps/wcm/connect/es/home/discover/cochlearimplants/ cochlear-implants-nucleus-system

Collazos, J. (30 de abril, 2014). Comunicación personal.

Congreso de la República de Colombia. Ley 30 del 28 de diciembre de 1992.
Congreso de la República de Colombia. Ley 115 del 08 de febrero de 1994.

Congreso de la República de Colombia. Ley 324 del 11 de octubre de 1996.

Congreso de la República de Colombia. Ley 361 del 07 de febrero de 1997.

Congreso de la República de Colombia. Ley 762 del 31 de julio de 2002.

Congreso de la República de Colombia. Ley 982 del 02 de agosto de 2005.

Congreso de la República de Colombia. Ley 1145 del 10 de julio de 2007.

Congreso de la República de Colombia. Ley 1346 del 31 de julio de 2009.

Congreso de la República de Colombia. Ley 1618 del 27 de febrero de 2013.

Consejo Nacional de Política Económica y Social. (2013). Política pública nacional de discapacidad e inclusión social. Bogotá: Departamento Nacional de Planeación.

Constitución Política de Colombia. (1991).

Corte Constitucional. Sentencia T- 002 de 1992. MP: Alejandro Martínez Caballero.

Corte Constitucional. Sentencia T- 429 de 1992. M. P.: Ciro Angarita Barón.

Corte Constitucional. Sentencia T-036 de 1993. M. P.: José Gregorio Hernández. 
Corte Constitucional. Sentencia T- 329 de 1997.

M. P.: Fabio Morón Díaz.

Corte Constitucional. Sentencia T- 513 de 1999.

M. P.: Martha Victoria Sáchica.

Corte Constitucional. Sentencia T-620 de 1999.

M. P.: Alejandro Martínez Caballero.

Corte Constitucional. Sentencia C-128 de 2002.

M. P.: Eduardo Montealegre Lynett.

Corte Constitucional. Sentencia C-067 de 2003.

M. P.: Marco Gerardo Monroy Cabra.

Corte Constitucional. Sentencia T-397 de 2004.

M. P.: Manuel José Cepeda Espinosa.

Corte Constitucional. Sentencia T-826 de 2004.

M. P.: Rodrigo Uprimny Yepes.

Corte Constitucional. Sentencia T-170 de 2007.

M.P.: Jaime Córdoba Triviño.

Corte Constitucional. Sentencia T-487 de 2007.

M. P.: Humberto Antonio Sierra Porto.

Corte Constitucional. Sentencia T-051 de 2011.

M. P.: Humberto Antonio Sierra Porto.

Corte Constitucional. Sentencia T-551 de 2011.

M. P.: Jorge Ignacio Pretelt.

Corte Constitucional. Sentencia T-694 de 2011.

M. P.: Jorge Iván Palacio Palacio.

Creswell, J. W. (2003). Research Design: Qualitative, Quantitative, and Mixed Method Approaches (2 ed.). Thousand Oaks.
Cuenca, P., Palacios, A., Ramiro, M. A., De Asís, R. y Barranco, M. del C. (2012). Estudios sobre los derechos de las personas sordas. Madrid, España: Dykinson

Departamento Administrativo Nacional de Estadística. (2008). Identificación de las personas con discapacidad en los territorios desde el rediseño del registro. Obtenido de DANE: http://www.dane.gov.co/files/investigaciones/discapacidad/identificacion\%20en\%20 los\%20territorios.pdf

Departamento Administrativo Nacional de Estadística. (2005). Censo general 2005. Obtenido de DANE: http://www.dane.gov.co/files/ censo2005/discapacidad.pdf

Federación Alemana de Sordos. (2006). Declaración de nuestra posición acerca de los implantes cocleares a niños con deficiencias auditivas. Obtenido de Cultura Sorda: http:// www.cultura-sorda.eu/resources/DGB_Declaracion_IC.pdf.

Federación Nacional de Sordos de Colombia. (1996). Lengua de señas colombiana. Bogotá: Fenascol.

Federación Nacional de Sordos de Colombia. (2011). Las personas sordas - Datos estadísticos registro DANE. Obtenido de FENASCOL:http://www.fenascol.org.co/index.php?option=com_content $\&$ view $=$ article $\&$ $\mathrm{id}=13 \&$ Itemid $=33 \&$ limitstart $=4$ 
Garzón, E. (5 de mayo, 2014). Comunicación personal.

Garzón Gil, G. (8 de mayo, 2014). Comunicación personal.

Glickman, N. S. (1993). Deaf identity development: Construction and validation of a theoretical model. Amherst, Massachusetts: University of Massachusetts at Amherst.

González, V. (2011). Un acercamiento histórico a la comunidad sorda de Colombia. Bogotá: Secretaría de Educación de Bogotá y Fenascol.

Hurtado Tarazona, A. (2004). Entre la integración y la diferenciación: la lucha por la reivindicación de los sordos como comunidad lingüística en Colombia. Bogotá: Ediciones Uniandes.

Martínez, D. P. (28 de febrero, 2014). Comunicación personal.

Ministerio de Educación Nacional. (2003). Resolución 2565 de octubre 24. Bogotá: MEN.

Ministerio de Educación Nacional. (2004). Educación para cada situación. Bogotá: MEN.

Recuperado de http://www.mineducacion.gov. co/1621/article-87346.html

Ministerio de Educación Nacional. (2009). Resultados de la Convocatoria del programa de innovación en educación superior para población con discapacidad. Recuperado de http://www.mineducacion.gov.co/1621/article-202159.html

Ministerio de Educación Nacional. (2013). Lineamientos. Política de educación superior inclusiva. Bogotá: men.

Moreno, M. (1996). Inclusión social, medios y discapacidad: el caso de la comunidad sorda de Colombia. Bogotá: Departamento de Comunicación Humana. Universidad Nacional de Colombia. Obtenido de portalcomunicacion: http://www.portalcomunicacion.com/ dialeg/paper/pdf/190_angarita.pdf

Moyano, D. (15 de abril, 2014). Comunicación personal.

Organización de las Naciones Unidas. (1948). Declaración Universal de Derechos Humanos.

Organización de las Naciones Unidas. (1976). Pacto Internacional de Derechos Económicos, Sociales y Culturales. Oficina del Alto Comisionado para los Derechos Humanos.

Organización de las Naciones Unidas. Unesco. (1990). Declaración Mundial sobre Educación para Todos.

Organización de las Naciones Unidas. Comité de Seguimiento. (1996). Declaración Universal de Derechos Lingüísticos.

Organización de las Naciones Unidas. Oficina del Alto Comisionado. (2006). Convención so- 
bre los derechos de las personas con discapacidad.

Organización de las Naciones Unidas. (2006). Convención Interamericana para la Eliminación de todas las Formas de Discriminación contra las Personas con Discapacidad.

Organización de las Naciones Unidas. (2011). Los derechos de las personas con discapacidad en el sistema de las Naciones Unidas. CoIombia. Bogotá: Oficina en Colombia del Alto Comisionado de las Naciones Unidas para los Derechos Humanos.

Organización de las Naciones Unidas. Comité de Derechos Económicos, Sociales y Culturales. Observaciones 13 y 15. Recuperado de http:// confdts1.unog.ch/1\%20SPA/Tradutek/Derechos_hum_Base/CESCR/00_1_obs_grales_ Cte\%20Dchos\%20Ec\%20Soc\%20Cult.html

Organización de las Naciones Unidas. Declaración de los Derechos de las Personas Sordas.

Organización Mundial de la Salud. (2001). Clasificación internacional del funcionamiento de la discapacidad y de la salud (CIF). Madrid: Ministerio de Trabajo y Asuntos Sociales. Secretaría de Estado de Servicios Sociales, Familias y Discapacidad. Instituto de Mayores y Servicios Sociales (IMSERSO).

Palacios, A. (Abril, 2008). El modelo social de discapacidad: orígenes, caracterización y plasmación en la Convención Internacional sobre los Derechos de las Personas con Discapacidad. Madrid: Grupo Editorial Cinca.
Palacios, A. (Abril, 2014). Seminario permanente de discusión crítica: "La legitimidad constitucional de la esterilización de las personas con discapacidad mental en Colombia". Universidad Externado de Colombia.

Parra Dussán, C. (6 de mayo, 2014). Comunicación personal.

Presidencia de la República. Decreto 907 del 23 de mayo de 1996.

Presidencia de la República. Decreto 2082 del 18 de noviembre de 1996.

Presidencia de la República. Decreto 2369 del 22 de septiembre de 1997.

Presidencia de la República. Decreto 3011 del 19 de diciembre de 1997.

Presidencia de la República. Decreto 366 del 09 de febrero de 2009.

Sánchez, C. (1992). La educación de los sordos en un modelo bilingüe. Mérida: Editorial lakonia.

Sarmiento, A. (2010). Situación de la educación en Colombia, preescolar, media y superior: una apuesta al cumplimiento del derecho a la educación para niños, niñas y jóvenes. Bogotá: Editorial Gente Nueva.

Valencia, S. (14 de marzo, 25 de abril 25 y 6 de mayo, 2014). Comunicación personal. 


\section{ANEXOS}

Tabla 1. Población con discapacidad en Colombia ${ }^{37}$

\begin{tabular}{|c|c|}
\hline Total de personas encuestadas & $41^{\prime} 242.948$ \\
\hline Total de personas con por lo menos una “limitación” & $\mathbf{2}$ '632.255 \\
\hline
\end{tabular}

\begin{tabular}{|l|c|}
\hline & Población \\
\hline Personas con “limitaciones” para ver & 143.992 \\
\hline Personas con “limitaciones” para caminar & $\mathbf{7 7 0 . 1 2 8}$ \\
\hline Personas con “limitaciones” para oír & 387.822 \\
\hline Personas con “limitaciones” para usar brazos y manos & 340.430 \\
\hline Personas con “limitaciones” para hablar & 315.601 \\
\hline Personas con “limitaciones” para entender aprender & 257.573 \\
\hline Personas con “limitaciones” para relacionarse con los demás & 247.113 \\
\hline Personas con “limitaciones” para su autocuidado & 494.683 \\
\hline Personas con otra “limitación” & \\
\hline
\end{tabular}

Fuente: dane: Censo general 2005. Recuperado de: http://www.dane.gov.co/files/censo2005/discapacidad.pdf

\section{Tabla 2. Tipos de discapacidad}

\begin{tabular}{|l|l|}
\hline \multicolumn{1}{|c|}{ Tipo de discapacidad } & \multicolumn{1}{c|}{ Explicación } \\
\hline Discapacidad sensorial & Comprende la discapacidad visual, auditiva y la sordoceguera. \\
\hline Discapacidad física o motora & $\begin{array}{l}\text { Se manifiesta en la limitación del movimiento, ausencia o parálisis de alguna extre- } \\
\text { midad. Algunos ejemplos son la paraplejia, la cuadriplejia, la amputación y la talla } \\
\text { baja. }\end{array}$ \\
\hline $\begin{array}{l}\text { Discapacidad cognitiva o intelec- } \\
\text { tual }\end{array}$ & $\begin{array}{l}\text { Se caracteriza por limitaciones significativas en el funcionamiento intelectual (es de- } \\
\text { cir, en el razonamiento, solución de problemas, pensamiento abstracto y planifica- } \\
\text { ción). Algunos ejemplos son el síndrome de Down y el síndrome de Asperger. }\end{array}$ \\
\hline Discapacidad mental ${ }^{2}$ & $\begin{array}{l}\text { Se presenta una alteración bioquímica que afecta la forma de pensar, los sentimien- } \\
\text { tos, el humor, la habilidad de relacionarse con otros y el comportamiento. Algunos } \\
\text { ejemplos son los trastornos de ansiedad y los trastornos depresivos. }\end{array}$ \\
\hline Discapacidad múltiple & Cuando se presenta más de una discapacidad. \\
\hline
\end{tabular}

Fuente: Fundación Saldarriaga Concha. (2013). Guía para periodistas. Discapacidad: claves para verla, oírla y comprenderla.

37 Se mantiene la terminología utilizada por el DANE a pesar de no estar de acuerdo con el concepto de "limitación" por tener una connotación negativa de la discapacidad. 
Tabla 3. Población (\%), según el tipo de discapacidad

\begin{tabular}{|l|c|}
\hline \multicolumn{1}{|c|}{ Variable } & Porcentaje (\%) frente a la población con discapacidad \\
\hline Discapacidad física & $43,9 \%$ \\
\hline Discapacidad visual & $\mathbf{4 3 , 4 \%}$ \\
\hline Discapacidad auditiva & $\mathbf{1 7 , 3 \%}$ \\
\hline Discapacidad para hablar & $\mathbf{1 3 , 0 \%}$ \\
\hline Discapacidad para atender o aprender & $\mathbf{1 1 , 7 \%}$ \\
\hline Discapacidad para relacionarse con los demás & $9,4 \%$ \\
\hline
\end{tabular}

Fuente: Fundación Saldarriaga Concha. (2013). Guía para periodistas. Discapacidad: claves para verla, oírla y comprenderla.

Tabla 4. Obstáculos discapacitantes y recomendaciones

\begin{tabular}{|c|l|}
\hline $\begin{array}{l}\text { Políticas y normas insufi- } \\
\text { cientes }\end{array}$ & $\begin{array}{l}\text { Sí existen políticas o normas pero no se cumplen. Además, la formulación de las políti- } \\
\text { cas no tiene en cuenta las necesidades de las personas con discapacidad. }\end{array}$ \\
\hline Actitudes negativas & $\begin{array}{l}\text { Son creadas por las creencias, prejuicios y estereotipos que se convierten en obstáculos } \\
\text { para que las personas con discapacidad accedan a la educación, a la salud, al empleo, } \\
\text { etc. }\end{array}$ \\
\hline $\begin{array}{l}\text { Prestación insuficiente de } \\
\text { servicios }\end{array}$ & $\begin{array}{l}\text { Las personas en condición de discapacidad son las directamente afectadas por las fallas } \\
\text { y deficiencias que presentan los servicios (de salud, de apoyo, de rehabilitación, etc.). }\end{array}$ \\
\hline $\begin{array}{l}\text { Problemas con la } \\
\text { prestación de servicios }\end{array}$ & $\begin{array}{l}\text { Las personas con discapacidad se ven afectadas por la mala coordinación de las en- } \\
\text { tidades prestadoras de servicios y por la falta de competencia que afecta la calidad, } \\
\text { accesibilidad e idoneidad de los servicios. }\end{array}$ \\
\hline Financiación insuficiente & $\begin{array}{l}\text { Los recursos destinados para las políticas y planes a favor de las personas con discapa- } \\
\text { cidad son insuficientes. }\end{array}$ \\
\hline Falta de accesibilidad & $\begin{array}{l}\text { Los edificios, sistemas de transporte, sistemas de información, entre otros, presentan } \\
\text { obstáculos que les impiden a las personas con discapacidad acceder a los servicios de } \\
\text { salud o a la búsqueda de empleo, por ejemplo. }\end{array}$ \\
\hline $\begin{array}{l}\text { Falta de consulta y partici- } \\
\text { pación }\end{array}$ & $\begin{array}{l}\text { A menudo se considera que las personas con discapacidad no son aptas para tomar } \\
\text { decisiones, incluso en cuestiones que afectan directamente su vida. }\end{array}$ \\
\hline Falta de datos y pruebas & $\begin{array}{l}\text { No existen datos ni cifras rigurosas y comparables sobre la discapacidad ni sobre los } \\
\text { programas que funcionan. Lo anterior impide que se adopten las medidas adecuadas. }\end{array}$ \\
\hline
\end{tabular}

Fuente: Organización Mundial de la Salud y Banco Mundial (2011). Informe mundial sobre la discapacidad. 
Tabla 5. Puntos de vista para estudiar lengua de señas

\begin{tabular}{|l|l|}
\hline \multicolumn{1}{|c|}{ Punto de vista } & \multicolumn{1}{c|}{ Descripción } \\
\hline Puramente lingüístico & La estructura interna de la lengua y su evolución histórica. \\
\hline Sociolingüístico & Relaciones de lenguaje, pensamiento y procesos de codificación y decodificación. \\
\hline Neurolingüístico & Procesos físicos correlativos al procesamiento del lenguaje. \\
\hline Social & $\begin{array}{l}\text { Relación entre lenguaje y actitudes de los hablantes/ejecutantes hacia la otra } \\
\text { lengua, modalidad del lenguaje y el tratamiento que el Estado debe tener frente a } \\
\text { la educación, etc. }\end{array}$ \\
\hline Diacrónico & $\begin{array}{l}\text { Procesos de cambio del lenguaje a lo largo del tiempo y en relación con lenguas } \\
\text { hermanas. }\end{array}$ \\
\hline
\end{tabular}

Fuente: Castellanos, S. (2010). La lengua de señas desde el punto de vista lingüístico.

\section{Tabla 6. Evolución de la población con discapacidad en la educación básica y media}

1. En 2003 , el $30 \%$ de los niños y niñas quedaban por fuera del sistema, mientras que en el 2008 el porcentaje era de 24\%. Aunque hay mejorías, los números muestran que 332.000 niñas y niños están por fuera del sistema educativo.

2. "La proporción de alumnos con discapacidad, en el año 2008 , se reduce significativamente frente a la lograda en el nivel de primaria. En efecto, mientras para primaria, la proporción nacional es 1,27\%, para secundaria, es menos de la mitad, 0,56\%, con una matrícula de 21,600 alumnos con discapacidad".

3. De los adolescentes con algún tipo de discapacidad solo asiste a clases un $12 \%$, mientras que los adolescentes $\sin$ discapacidad asisten en un $72,9 \%$. Es evidente que la cifra de niños, niñas y adolescentes con discapacidad excluidos del sistema educativo es muy alta, teniendo en cuenta factores como la entrada tardía al sistema, entrada a un sistema no formal de educación y la deserción de la mayoría de estos estudiantes.

4. Para el año 2008 Colombia estaba ubicado entre los países de América Latina con más alta deserción en el ciclo secundario - la tasa de deserción es del 27,8\%, una cifra que solo la supera México-.

5. La educación media es la menos atendida: "A pesar de un muy inusual crecimiento de más del $60 \%$ de asistentes entre 2005 y 2008, apenas se cubre un poco más de la cuarta parte de la población objetivo". El problema central es la insuficiente oferta educativa.

6. En el 2008 las personas con discapacidad matriculadas en educación básica no eran más del 0,4\% —cerca de la mitad del registrado para la secundaria básica $(0,7 \%)$ - El abandono y la deserción son evidentes en la educación secundaria de las personas que cuentan con algún tipo de discapacidad.

Fuente: Sarmiento, A. (2010). Situación de la educación en Colombia, preescolar, media y superior: una apuesta al cumplimiento del derecho a la educación para niños, niñas y jóvenes. 
Tabla 7. Nivel educativo de las personas con discapacidad auditiva ${ }^{39}$

\begin{tabular}{|c|c|c|}
\hline & Número de personas & Porcentaje \\
\hline $\begin{array}{c}\text { Han asistido a instituciones especiales } \\
\text { para sordos }\end{array}$ & 327 & $54.3 \%$ \\
\hline Han asistido a instituciones para oyentes & 80 & $13.3 \%$ \\
\hline $\begin{array}{c}\text { Han asistido a instituciones de las dos } \\
\text { clases }\end{array}$ & 199 & $32.4 \%$ \\
\hline
\end{tabular}

ALFABETIZACIÓN

\begin{tabular}{|c|c|c|}
\hline & Número de personas & Porcentaje \\
\hline Saben leer & 87 & $13.5 \%$ \\
\hline Escriben párrafos & 72 & $11.2 \%$ \\
\hline No saben leer & 110 & $17 \%$ \\
\hline Leen pero no entienden & 118 & $18.4 \%$ \\
\hline No saben escribir & 100 & $16 \%$ \\
\hline
\end{tabular}

\begin{tabular}{|c|c|}
\hline Nivel de educación alcanzado & Porcentaje \\
\hline Algún grado de secundaria & $33.5 \%$ \\
\hline Algún grado de educación superior 40 & $3.1 \%$ \\
\hline
\end{tabular}

Fuente: Fenascol. (2011). Las personas sordas. Datos estadísticos registro Dane. Disponible en http://www.fenascol.org.co/index.php?option=com_content\&view=article\&id=13\&ltemid=33\&limitstart=4

Tabla 8. Grupos representativos de las falencias del sistema de educación colombiano ${ }^{41}$

\begin{tabular}{|l|}
\hline i) Personas en situación de discapacidad y con capacidades o talentos excepcionales \\
\hline ii) Grupos étnicos (comunidades negras, afrocolombianas, raizales y palenqueras), pueblos indígenas y pueblo Rom \\
\hline iii) Población víctima, según lo estipulado en el artículo tercero de la Ley 1448 de 2011 \\
\hline iv) Población desmovilizada en proceso de reintegración \\
\hline v) Población habitante de frontera
\end{tabular}

Fuente: Ministerio de Educación Nacional. (2013). Lineamientos de política de educación superior inclusiva.

39 La educación se analizó con base en los siguientes indicadores: i) alfabetización, entendida como la capacidad para leer y escribir; ii) asistencia a instituciones educativas formales o especializadas; iii) nivel educativo alcanzado: primaria, bachillerato y universidad. Población: 602 personas encuestadas que dicen haber asistido a alguna institución educativa.

40 En carreras como auxiliar de contabilidad, sistemas, dibujo publicitario, dibujo arquitectónico y decoración, filosofía y ciencias religiosas, licenciatura en pedagogía reeducativa, licenciatura en educación básica primaria, artes plásticas, pedagogía (Fenascol, 2011).

41 Cada uno de estos grupos requiere de acciones precisas de política pública, de ahí la importancia de diferenciarlos, identificarlos y conocerlos a profundidad. Para el MEN (2013), el estudio de estos grupos se debe enmarcar en un enfoque diferencial, "definido como un método de análisis y de acción que hace visibles las formas de exclusión de la educación superior de los estudiantes de los grupos mencionados para, tomando en cuenta esta visibilización, brindar adecuada protección en el sistema". 
Tabla 9. Barreras y estrategias que existen para la población estudiantil en situación de discapacidad

\begin{tabular}{|c|c|c|}
\hline Variable & Barrera & Acción estratégica \\
\hline \multirow[t]{3}{*}{ Acceso } & $\begin{array}{l}\text { 1. El acceso a la información sobre la oferta } \\
\text { de créditos educativos y otros mecanismos de } \\
\text { financiación, tanto del ICETEX como de entida- } \\
\text { des privadas es insuficiente para la población } \\
\text { con discapacidad. }\end{array}$ & $\begin{array}{l}\text { 1. Implementar el Sistema de Orientación Vocacio- } \\
\text { nal y Profesional con el apoyo de las secretarías de } \\
\text { educación departamental, el ICFES y el ICETEX, para } \\
\text { la difusión de material que permita el acceso a la in- } \\
\text { formación tanto de instituciones como de programas } \\
\text { educativos del nivel superior, así como de los meca- } \\
\text { nismos de financiación y permanencia en este nivel. } \\
\text { 2. Promover estrategias de movilización de la de- } \\
\text { manda hacia la educación superior, fortaleciendo las } \\
\text { capacidades institucionales locales para una perma- } \\
\text { nente dinamización de acciones de orientación voca- } \\
\text { cional y profesional. } \\
\text { 3. Hacer seguimiento y evaluar las condiciones de ac- } \\
\text { ceso, permanencia y graduación de las personas con } \\
\text { discapacidad o con talentos excepcionales, en coor- } \\
\text { dinación con las instituciones de educación superior } \\
\text { (IES), los centros de investigación y otras entidades } \\
\text { del sector, a través de los sistemas de información de } \\
\text { la educación superior (sNIES, SPADIES, OLE). } \\
\text { 4. Fomentar el acceso y permanencia de las personas } \\
\text { con discapacidad o talentos excepcionales a través } \\
\text { de líneas de financiación para pregrado y posgrado } \\
\text { ofertadas a través del ICETEX. }\end{array}$ \\
\hline & $\begin{array}{l}\text { 2. Las pruebas de admisión de las IES y las } \\
\text { pruebas de Estado del ICFES son inadecuadas } \\
\text { para las necesidades específicas de la pobla- } \\
\text { ción con discapacidad. }\end{array}$ & $\begin{array}{l}\text { 1. Fomentar en las IES la flexibilización y adaptación de } \\
\text { procesos de selección y evaluación para el ingreso de } \\
\text { aspirantes con discapacidad o talentos excepcionales. } \\
\text { Adoptar criterios de inclusión, adaptabilidad y accesi- } \\
\text { bilidad de acuerdo con las necesidades y los apoyos } \\
\text { particulares requeridos por las poblaciones } \\
\text { 2. Coordinar acciones con el Instituto Colombiano } \\
\text { para la Evaluación de la Calidad (ICFES) orientadas al } \\
\text { ajuste y la flexibilización de las pruebas SABER 11o } \\
\text { (Examen de Estado para el Ingreso a Educación Supe- } \\
\text { rior) y el Examen de Estado de Calidad de la Educación } \\
\text { Superior (ECAES SABER PRO), adoptando criterios de } \\
\text { adaptabilidad y accesibilidad de acuerdo con las ne- } \\
\text { cesidades y los apoyos particulares requeridos por la } \\
\text { población con discapacidad o talentos excepcionales. }\end{array}$ \\
\hline & $\begin{array}{l}\text { 3. Los procesos de articulación de la educación } \\
\text { media con la educación superior no tienen en } \\
\text { cuenta las necesidades pedagógicas de la po- } \\
\text { blación con discapacidad o talentos excepcio- } \\
\text { nales. }\end{array}$ & $\begin{array}{l}\text { Fortalecer los procesos de articulación de la educación } \\
\text { media con la educación superior que involucren la po- } \\
\text { blación con discapacidad o talentos excepcionales y } \\
\text { que garanticen su acceso en óptimas condiciones y su } \\
\text { permanencia en el sistema educativo. }\end{array}$ \\
\hline
\end{tabular}




\begin{tabular}{|c|c|c|}
\hline Permanencia & $\begin{array}{l}\text { 1. Los avances en la eliminación de barreras ar- } \\
\text { quitectónicas y urbanísticas, que obstaculizan } \\
\text { el acceso y permanencia de la población con } \\
\text { discapacidad o talentos excepcionales en las } \\
\text { IES son mínimos y parciales. }\end{array}$ & $\begin{array}{l}\text { Promover la eliminación de las barreras arquitectóni- } \\
\text { cas y urbanísticas en las IES exigiendo el cumplimiento } \\
\text { de las normas de accesibilidad contenidas en la Ley } \\
361 \text { de } 1997 \text { y demás relacionadas, a través de con- } \\
\text { vocatorias proyectadas que fomenten la construcción } \\
\text { y adecuación de infraestructura en las IES a nivel na- } \\
\text { cional. }\end{array}$ \\
\hline & $\begin{array}{l}\text { 2. El pago de los servicios de interpretación en } \\
\text { las IES corre por cuenta de la persona sorda } \\
\text { o su familia, lo cual representa doble carga } \\
\text { económica y afecta la permanencia. }\end{array}$ & $\begin{array}{l}\text { 1. Promover la disponibilidad de intérpretes de Len- } \\
\text { gua de Señas Colombiana (LSC), guías-intérpretes en } \\
\text { las IES y el apoyo técnico, visual y didáctico pertinente. } \\
\text { 2. Fomentar la acreditación y profesionalización de } \\
\text { intérpretes. } \\
\text { 3. Promover la creación de fondos para cubrir los gas- } \\
\text { tos complementarios en educación superior de las } \\
\text { personas con discapacidad }\end{array}$ \\
\hline & $\begin{array}{l}\text { 3. Los apoyos profesionales que requiere cada } \\
\text { una de las personas con discapacidad o talen- } \\
\text { tos excepcionales son insuficientes. }\end{array}$ & $\begin{array}{l}\text { Promover dentro de las IES políticas institucionales } \\
\text { que permitan a los estudiantes acceder a servicios y } \\
\text { apoyos complementarios que les faciliten su adap- } \\
\text { tación al medio universitario. }\end{array}$ \\
\hline Pertinencia & $\begin{array}{l}\text { 1. Las personas con diferentes tipos de discapa- } \\
\text { cidad carecen de una oferta académica especí- } \\
\text { fica y están al margen del diseño y construc- } \\
\text { ción de propuestas curriculares diferenciales. }\end{array}$ & $\begin{array}{l}\text { 1. Coordinar con el Consejo Nacional de Acreditación } \\
\text { (CNA) y con la Comisión Nacional Intersectorial de } \\
\text { Aseguramiento de la Calidad (CONACES), la incorpora- } \\
\text { ción de criterios de educación inclusiva y accesibilidad } \\
\text { en el Sistema de Aseguramiento de la Calidad de la } \\
\text { Educación Superior. } \\
\text { 2. Promover la creación de mecanismos de adecua- } \\
\text { ción y flexibilización de contenidos, prácticas peda- } \\
\text { gógicas y de diseño curricular, teniendo en cuenta las } \\
\text { particularidades culturales, lingüísticas y de excepcio- } \\
\text { nalidad de estudiantes, adoptando los estándares in- } \\
\text { ternacionales de acceso universal. }\end{array}$ \\
\hline
\end{tabular}




\begin{tabular}{|c|c|c|}
\hline & $\begin{array}{l}\text { 2. El avance en el acceso de la oferta académi- } \\
\text { ca para personas con discapacidad a través de } \\
\text { las TIC y de metodologías flexibles es escaso. }\end{array}$ & $\begin{array}{l}\text { 1. Fomentar el desarrollo de ambientes virtuales de } \\
\text { aprendizaje (AVA) y objetos virtuales de aprendizaje } \\
\text { (OVA) que contribuyan a la adecuación y flexibilización } \\
\text { de la oferta de programas académicos del país en co- } \\
\text { rrespondencia con la diversidad. } \\
\text { 2. Brindar incentivos a las IES que adelanten procesos } \\
\text { de adaptación y creación de programas académicos } \\
\text { flexibles con uso de TIC, bajo estándares que garan- } \\
\text { tices las condiciones de acceso universal y accesibili- } \\
\text { dad respondiendo a la diversidad de la población con } \\
\text { discapacidad o talentos excepcionales. } \\
\text { 3. Fortalecer el acceso a la información y a las nuevas } \\
\text { tecnologías en las IES, desde la perspectiva de la inclu- } \\
\text { sión y la interculturalidad, a partir de la producción } \\
\text { de ova, de la implementación de software, del uso de } \\
\text { equipos de cómputo y adaptación de contenidos y de } \\
\text { páginas web, respondiendo a los estándares interna- } \\
\text { cionales de acceso universal - W3C. } \\
\text { 4. Motivar la adquisición de bibliografía especializada } \\
\text { en braille, libro hablado y otros productos tiflológicos } \\
\text { necesarios para la población. }\end{array}$ \\
\hline & $\begin{array}{l}\text { 3. La oferta laboral para las personas con dis- } \\
\text { capacidad que egresan de las IES no responde } \\
\text { a las expectativas y al perfil para el cual fueron } \\
\text { formadas y las condiciones, cuando acceden al } \\
\text { mundo laboral, son inequitativas (mayor carga } \\
\text { laboral, baja remuneración, falta de trabajo en } \\
\text { equipo, discriminación, etc.). }\end{array}$ & $\begin{array}{l}\text { 1. Fortalecer el sistema de seguimiento a graduados/ } \\
\text { as a través del Observatorio Laboral para la Educación } \\
\text { Superior que incluya variables que permitan hacer se- } \\
\text { guimiento a la población con discapacidad o talentos } \\
\text { excepcionales. } \\
\text { 2. Articular acciones con el Ministerio de Trabajo con } \\
\text { el fin de formular políticas públicas que adecúen la } \\
\text { oferta laboral a la formación de los estudiantes con } \\
\text { discapacidad. }\end{array}$ \\
\hline Calidad & $\begin{array}{l}\text { 1. La falta de formación diferencial tanto para } \\
\text { docentes como para la comunidad educativa } \\
\text { es una limitación para generar procesos de } \\
\text { educación inclusiva al interior de las IES. }\end{array}$ & $\begin{array}{l}\text { 1. Desarrollar y fortalecer la oferta en educación su- } \\
\text { perior para la formación docente, que incluya la va- } \\
\text { riable de personas con discapacidad o talentos excep- } \\
\text { cionales. } \\
\text { 2. Promover el respeto por la diversidad, la elimina- } \\
\text { ción de estereotipos, estigmas, prácticas de discrimi- } \\
\text { nación y prejuicios sobre las personas con discapaci- } \\
\text { dad o talentos excepcionales, a través de procesos de } \\
\text { sensibilización, información y formación de directivos } \\
\text { de IES y de la comunidad académica en general sobre } \\
\text { la educación inclusiva, la discapacidad y sus implica- } \\
\text { ciones. }\end{array}$ \\
\hline
\end{tabular}




\begin{tabular}{|l|l|l|}
\hline & $\begin{array}{l}\text { 1. Fomentar la creación de líneas de investigación y } \\
\text { ceso, permanencia y promoción de estudian- } \\
\text { tes con discapacidad o talentos excepcionales } \\
\text { en el ámbito de la educación superior es insu- } \\
\text { ficiente. }\end{array}$ & $\begin{array}{l}\text { semilleros que permitan innovar en mecanismos para } \\
\text { brindar el servicio educativo o la población con disca- } \\
\text { pacidad o talentos excepcionales. }\end{array}$ \\
$\begin{array}{ll}\text { 2. Reconocer y apoyar la réplica de experiencias signi- } \\
\text { ficativas de inclusión, de personas con discapacidad o } \\
\text { talentos excepcionales adelantadas por las IES colom- } \\
\text { bianas, a través de recursos tecnológicos y pedagógi- } \\
\text { cos, así como divulgar las experiencias internacionales } \\
\text { en la materia. }\end{array}$ \\
\hline $\begin{array}{l}\text { 3. La esfera académica que profesionaliza o o } \\
\text { profundiza la formación de intérpretes es in- } \\
\text { suficiente para cumplir con una interpretación } \\
\text { de calidad. }\end{array}$ & $\begin{array}{l}\text { 1. Promover la investigación y enseñanza de la LSc } \\
\text { como lengua de las personas sordas. }\end{array}$ \\
$\begin{array}{l}\text { 2. Fomentar la creación de programas de formación de } \\
\text { intérpretes para sordos y sordociegos desde las facul- } \\
\text { tades de ciencias humanas en las IES colombianas. }\end{array}$ \\
$\begin{array}{l}\text { cuadas, que fomenten la permanencia de las } \\
\text { personas con discapacidad o talentos excep- } \\
\text { cionales. }\end{array}$ & $\begin{array}{l}\text { Promover la creación de un semestre cero, de nivela- } \\
\text { ción o preuniversitario, que permita reducir la brecha } \\
\text { en las competencias requeridas por la población con } \\
\text { discapacidad o talentos excepcionales para el desarro- } \\
\text { llo de carreras técnicas, tecnológicas o profesionales. }\end{array}$ \\
\hline
\end{tabular}

Fuente: Ministerio de Educación Nacional. (2013). Lineamientos de política de educación superior inclusiva.

Tabla 10. Conclusiones del documento Lineamientos de política de educación superior inclusiva

1. En el 2013 la tasa de cobertura en educación superior fue de $45.5 \%$. Esta cifra se obtuvo teniendo en cuenta el número de estudiantes matriculados en pregrado sobre el total de la población entre 17 y 21 años. En el 2010, la tasa de cobertura fue del $37 \%$. El aumento en tres años fue de $8.5 \%$.

2. Según los datos más actualizados de la Unesco, Colombia está detrás de varios países latinoamericanos en lo que se refiere a cobertura: Cuba $(80,4 \%)$, Venezuela $(78,1 \%)$, Argentina $(74,8 \%)$, Chile $(70,7 \%)$ y Uruguay $(63,2 \%)$.

3. Entre los años 2010 y 2013 se redujo la tasa de deserción de $12.9 \%$ al 10.6\%, es decir, un 2,3\%. La anterior cifra se traduce en aproximadamente 39.000 jóvenes que permanecieron en el sistema y que no desertaron.

4. En cuanto al acceso, desde el 2010 se han creado aproximadamente 429.999 cupos nuevos en educación superior.

5. En relación con la graduación, se ha fortalecido la educación pública superior en el país, puesto que pasó de otorgar el $41 \%$ de los títulos en el 2003 , al $49 \%$ en el 2012 . La brecha entre educación pública y privada se redujo en un $2 \%$.

6. Los esfuerzos realizados por Colombia para mejorar el acceso a la educación, la permanencia, la calidad, la pertinencia y la graduación en la educación superior, hacen que ocupe el puesto 61, entre 148 países, en términos de competitividad, de acuerdo con el reciente Reporte global de competitividad del Foro Económico Mundial.

Fuente: Ministerio de Educación Nacional. (2013). Lineamientos de política de educación superior inclusiva. 